\title{
Rapid Feedforward Inhibition and Asynchronous Excitation Regulate Granule Cell Activity in the Mammalian Main Olfactory Bulb
}

\author{
(1) Shawn D. Burton ${ }^{1,2}$ and $\odot$ Nathaniel N. Urban ${ }^{1,2,3}$ \\ ${ }^{1}$ Department of Biological Sciences, Carnegie Mellon University, Pittsburgh, Pennsylvania 15213, ${ }^{2}$ Center for the Neural Basis of Cognition, Pittsburgh, \\ Pennsylvania 15213, and ${ }^{3}$ Department of Neurobiology, University of Pittsburgh, Pittsburgh, Pennsylvania 15213
}

Granule cell-mediated inhibition is critical to patterning principal neuron activity in the olfactory bulb, and perturbation of synaptic input to granule cells significantly alters olfactory-guided behavior. Despite the critical role of granule cells in olfaction, little is known about how sensory input recruits granule cells. Here, we combined whole-cell patch-clamp electrophysiology in acute mouse olfactory bulb slices with biophysical multicompartmental modeling to investigate the synaptic basis of granule cell recruitment. Physiological activation of sensory afferents within single glomeruli evoked diverse modes of granule cell activity, including subthreshold depolarization, spikelets, and suprathreshold responses with widely distributed spike latencies. The generation of these diverse activity modes depended, in part, on the asynchronous time course of synaptic excitation onto granule cells, which lasted several hundred milliseconds. In addition to asynchronous excitation, each granule cell also received synchronous feedforward inhibition. This inhibition targeted both proximal somatodendritic and distal apical dendritic domains of granule cells, was reliably recruited across sniff rhythms, and scaled in strength with excitation as more glomeruli were activated. Feedforward inhibition onto granule cells originated from deep short-axon cells, which responded to glomerular activation with highly reliable, short-latency firing consistent with tufted cell-mediated excitation. Simulations showed that feedforward inhibition interacts with asynchronous excitation to broaden granule cell spike latency distributions and significantly attenuates granule cell depolarization within local subcellular compartments. Collectively, our results thus identify feedforward inhibition onto granule cells as a core feature of olfactory bulb circuitry and establish asynchronous excitation and feedforward inhibition as critical regulators of granule cell activity.

Key words: disinhibition; feedforward inhibition; olfaction; olfactory bulb; synaptic integration

Significance Statement

Inhibitory granule cells are involved critically in shaping odor-evoked principal neuron activity in the mammalian olfactory bulb, yet little is known about how sensory input activates granule cells. Here, we show that sensory input to the olfactory bulb evokes a barrage of asynchronous synaptic excitation and highly reliable, short-latency synaptic inhibition onto granule cells via a disynaptic feedforward inhibitory circuit involving deep short-axon cells. Feedforward inhibition attenuates local depolarization within granule cell dendritic branches, interacts with asynchronous excitation to suppress granule cell spike-timing precision, and scales in strength with excitation across different levels of sensory input to normalize granule cell firing rates.

\section{Introduction}

Sensory encoding in the mammalian main olfactory bulb (MOB) depends critically on granule cell (GC)-mediated inhibition to

\footnotetext{
Received Feb. 23, 2015; revised Aug. 12, 2015; accepted Aug. 18, 2015.

Author contributions: S.D.B. and N.N.U. designed research; S.D.B. performed research; S.D.B. analyzed data; S.D.B. and N.N.U. wrote the paper.

This work was supported by National Institute on Deafness and Other Communication Disorders Grants F31DC013490 (S.D.B.), R01DC005798 (N.N.U.), and R01DC011184 (N.N.U.) and the Pennsylvania Department of Health Commonwealth Universal Research Enhancement Program (N.N.U.). We thank Greg LaRocca and the Mellon Institute Centralized Vivarium staff for excellent technical assistance and members of the Urban, Barth, Gittis, Kuhlman, Ermentrout, and Oswald laboratories for helpful discussions.
}

(1) decorrelate principal neuron activity downstream of overlapping sensory input (Bathellier et al., 2008; Cury and Uchida, 2010; Kato et al., 2012) and (2) temporally pattern principal neuron activity within network rhythms (Friedman and Strowbridge, 2003; Neville and Haberly, 2003; Lagier et al., 2004; Bathellier et al., 2006; Schoppa, 2006b; Lepousez and Lledo, 2013;

The authors declare no competing financial interests.

Correspondence should be addressed to Nathaniel N. Urban, Department of Neurobiology, University of Pittsburgh, E1440 BSTWR, 200 Lothrop Street, Pittsburgh, PA 15213. E-mail: nurban@pitt.edu.

DOI:10.1523/JNEUROSCI.0746-15.2015

Copyright $\odot 2015$ the authors $\quad 0270-6474 / 15 / 3514103-20 \$ 15.00 / 0$ 
Fukunaga et al., 2014). Consequently, disruption of GC recruitment by selective perturbation of synaptic excitation or inhibition onto GCs significantly alters MOB network rhythms and odor discrimination (Nusser et al., 2001; Abraham et al., 2010; Nunez-Parra et al., 2013). Thus, understanding how sensory input recruits GCs will be a crucial step in understanding olfaction, yet to date, no study has examined how GCs integrate synaptic excitation and inhibition.

GCs fire at low rates and long latencies in vivo (Wellis and Scott, 1990; Luo and Katz, 2001; Cang and Isaacson, 2003; Margrie and Schaefer, 2003; Labarrera et al., 2013; Cazakoff et al., 2014; Fukunaga et al., 2014). This sparse, long-latency activity at least partially arises from GC intrinsic properties (Schoppa and Westbrook, 1999; Kapoor and Urban, 2006; Schoppa, 2006a; Pressler et al., 2007; Egger, 2008; Stroh et al., 2012). Unique features of synaptic excitation onto GCs likely also regulate GC recruitment. GCs receive excitation at reciprocal dendrodendritic synapses formed with principal mitral (MCs) and tufted (TCs) cells. Several recent studies have demonstrated that physiological activation of MOB sensory afferents evokes rapid TC firing but delayed MC firing (Fukunaga et al., 2012; Gire et al., 2012; Igarashi et al., 2012; Burton and Urban, 2014). Thus, the temporal structure of synaptic excitation may play a critical role in shaping GC activity.

Synaptic inhibition onto GCs may also contribute to the low rates and long latencies observed in GCs. Surprisingly, however, how inhibition influences GC activity has received almost no attention, despite the early emergence (Carleton et al., 2003; Panzanelli et al., 2009; Arenkiel et al., 2011; Deshpande et al., 2013) and central role of GABAergic inputs in the integration and maturation of adult-born GCs (Pallotto et al., 2012). Indeed, odors drive synaptic inhibition onto GCs in vivo (Labarrera et al., 2013), and all mature GCs receive functional inhibitory inputs throughout their somatodendritic axis (Price and Powell, 1970a; Panzanelli et al., 2009; Nunez-Parra et al., 2013). However, when and how synaptic inhibition regulates GC activity is not currently known.

Here, we investigate the synaptic basis of GC recruitment using in vitro patch-clamp electrophysiology and biophysical multicompartmental modeling. We demonstrate that the sparse, long-latency GC firing observed in vivo depends on the combination of (1) asynchronous synaptic excitation and (2) rapid, synchronous feedforward GABAergic inhibition, a previously unreported feature of the MOB circuit. Critically, feedforward inhibition not only regulates GC spiking, but dendrite-targeting inhibition can attenuate depolarization within local spines, providing a candidate mechanism for regulating subcellular calcium dynamics to control the balance between dendrodendritic recurrent and lateral inhibition of MCs/TCs.

\section{Materials and Methods}

Ethical approval. All experiments were completed in compliance with the guidelines established by the Institutional Animal Care and Use Committee of Carnegie Mellon University.

Animals. A combination of Thy1-YFP-G ( $n=15$; Feng et al., 2000), C57BL/6 $(n=16)$, albino C57BL/6J $(n=13)$, and albino C57BL/6J mice crossed to gene-targeted mice expressing the H134R variant of channelrhodopsin-2 fused to enhanced yellow fluorescent protein (ChR2:EYFP) from the olfactory marker protein (OMP) locus (OMPChR2:EYFP; $n=24$ ) were used in this study. OMP-ChR2:EYFP mice selectively express ChR2:EYFP in the presynaptic terminals of mature olfactory sensory neurons (OSNs; Smear et al., 2011). Only heterozygous OMP-ChR2:EYFP animals and wild-type littermates were used, because complete loss of OMP expression leads to alterations in olfactory percep- tion (Youngentob and Margolis, 1999; Youngentob et al., 2004; Lee et al., 2011; Kass et al., 2013a,b) and deficits in OSN axonal targeting (St John and Key, 2005) and OSN activation and signaling (Buiakova et al., 1996; Ivic et al., 2000; Youngentob et al., 2003; Reisert et al., 2007; Lee et al., 2011; Kass et al., 2013b).

Slice preparation. Postnatal day 18-28 mice of both sexes were anesthetized with isoflurane and decapitated into ice-cold oxygenated dissection solution containing the following (in $\mathrm{mM}$ ): $125 \mathrm{NaCl}, 25$ glucose, 2.5 $\mathrm{KCl}, 25 \mathrm{NaHCO}_{3}, 1.25 \mathrm{NaH}_{2} \mathrm{PO}_{4}, 3 \mathrm{MgCl}_{2}$, and $1 \mathrm{CaCl}_{2}$. Brains were isolated rapidly, and acute horizontal slices ( $310 \mu \mathrm{m}$ thick) of the $\mathrm{MOB}$ were prepared using a vibratome (5000 mz-2; Campden Instruments). Slices recovered for $30 \mathrm{~min}$ in $\sim 37^{\circ} \mathrm{C}$ oxygenated Ringer's solution that was identical to the dissection solution except for lower $\mathrm{Mg}^{2+}$ concentrations $\left(1 \mathrm{~mm} \mathrm{MgCl}_{2}\right)$ and higher $\mathrm{Ca}^{2+}$ concentrations $(2 \mathrm{~mm} \mathrm{CaCl} 2)$. Slices were then stored in room temperature oxygenated Ringer's solution until recording.

Electrophysiology. Slices were superfused continuously with warmed oxygenated Ringer's solution (temperature measured in bath, $32^{\circ} \mathrm{C}$ ). Cells were visualized using infrared differential interference contrast video microscopy. Recordings were concentrated in the medial half of each horizontal MOB slice, in which individual glomeruli and OSN bundles are frequently visible and MC and TC apical dendrites run parallel to the cutting plane and are thus predominantly intact (cf. Borisovska et al., 2011). GC and deep short-axon cell (dSAC) spiking activity was recorded in current-clamp mode from holding potentials of $-61.9 \pm 2.3 \mathrm{mV}(n=$ $31)$ and $-66.2 \pm 4.4 \mathrm{mV}(n=10)$, respectively, using electrodes (final electrode resistance of $7.4 \pm 1.1 \mathrm{M} \Omega, n=51$ ) filled with the following: $120 \mathrm{~mm}$ K-gluconate, $2 \mathrm{~mm} \mathrm{KCl}, 10 \mathrm{~mm}$ HEPES, $10 \mathrm{~mm} \mathrm{Na}$ phosphocreatine, 4 mm Mg-ATP, $0.3 \mathrm{~mm} \mathrm{Na}_{3}$ GTP, 0.2 mм EGTA, 0.25 mм Alexa Fluor 594 (Life Technologies), and 0.2\% Neurobiotin (Vector Laboratories). Cells exhibiting resting membrane potentials greater than $-50 \mathrm{mV}$ (frequently with high spontaneous firing rates) were excluded from analysis. Synaptic input to GCs was recorded in voltage-clamp mode using electrodes $(6.9 \pm 1.2 \mathrm{M} \Omega, n=56)$ filled with the following: 140 mm Cs-gluconate, 10 mм QX-314, 2 mм KCl, 10 mм HEPES, 10 mм Na-phosphocreatine, 4 mm Mg-ATP, 0.3 mm Na $\mathrm{NTP}_{3} 0.25 \mathrm{~mm}$ Alexa Fluor 594, and $0.2 \%$ Neurobiotin. TC spiking and synaptic activity was recorded using electrodes $(7.1 \pm 1.7 \mathrm{M} \Omega, n=7)$ filled with the K-based solution. Liquid junction potentials were $12-14 \mathrm{mV}$ (K-based solution) and $11 \mathrm{mV}$ (Cs-based solution) and were not corrected for. Cell morphology was reconstructed under a $100 \times$ oil-immersion objective and analyzed with Neurolucida (MBF Bioscience). GCs were classified as deep GCs (dGCs; also known as "type II granule cells") if their apical dendrites branched within or beneath the mitral cell layer (MCL) and their apical dendritic spines were visibly concentrated in the lower half of the external plexiform layer (EPL; Fig. 1A), as described previously (Mori et al., 1983; Orona et al., 1983). Likewise, GCs were classified as superficial GCs (sGCs; also known as "type III granule cells") if their apical dendrites branched within the EPL and their apical dendritic spines were visibly concentrated in the upper half of the EPL (Fig. 1A). A small subset of GCs could not be classified conclusively as sGCs or dGCs and were not included in comparisons of sGCs and dGCs. As noted previously (Mori et al., 1983; Orona et al., 1983), GC soma position partially predicted GC type, with GCs in the MCL or upper granule cell layer (GCL) often exhibiting sGC morphologies and GCs in the lower GCL often exhibiting dGC morphologies. dSACs were identified by their large soma size and inframitral soma position. In addition, GCs could be distinguished easily from dSACs by their passive membrane properties measured in response to a small hyperpolarizing step current injection (Table 1), as well as by their action potential and spike train properties measured in response to a series of depolarizing step current injections (Tables 2, 3, respectively). Electrophysiological data were low-pass filtered at $4 \mathrm{kHz}$ and digitized at $10 \mathrm{kHz}$ using a MultiClamp 700A amplifier (Molecular Devices) and an ITC-18 acquisition board (InstruTech) controlled by custom software written in IGOR Pro (WaveMetrics). In current-clamp recordings, pipette capacitance was neutralized, and series resistance (GCs, $37.1 \pm 8.7$ $\mathrm{M} \Omega, n=41$; dSACs, $30.3 \pm 6.8 \mathrm{M} \Omega, n=10$ ) was compensated using the MultiClamp Bridge Balance operation. In voltage-clamp recordings, series resistance (GCs, $31.6 \pm 8.4, n=56$ ) was typically not compensated 
A

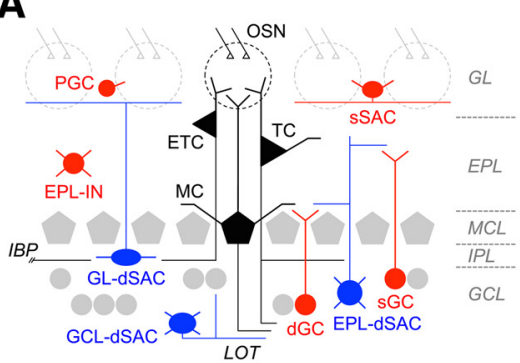

C
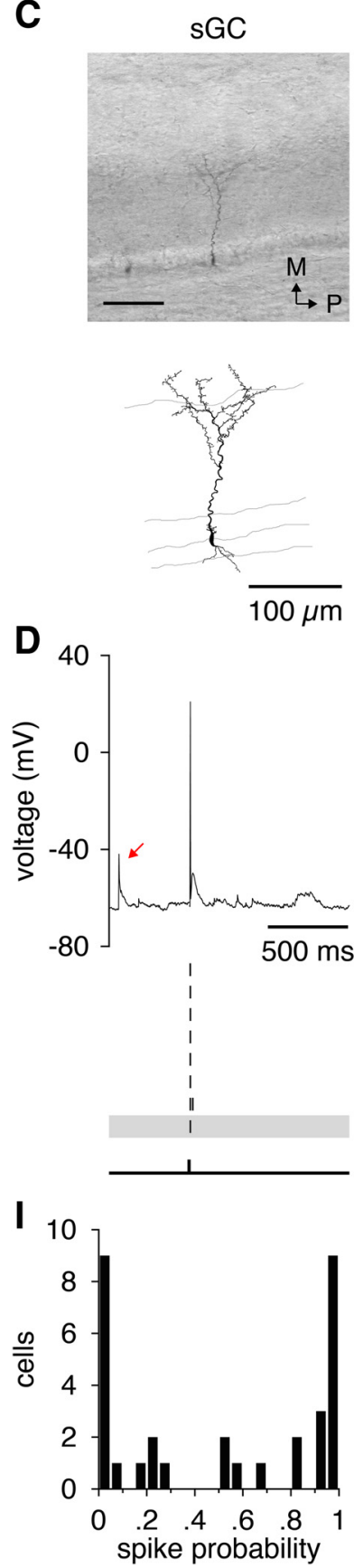

B

E

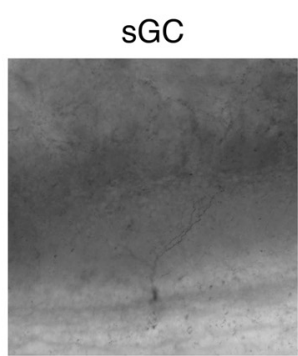

F
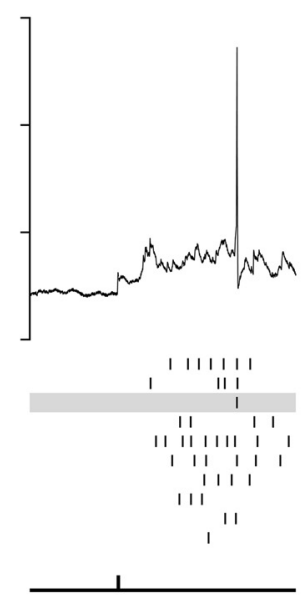

J

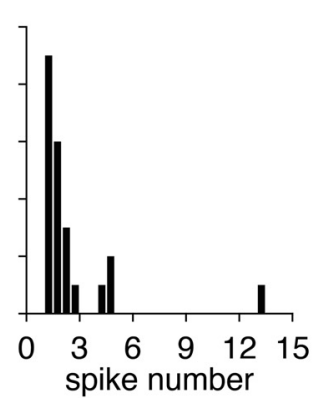

G
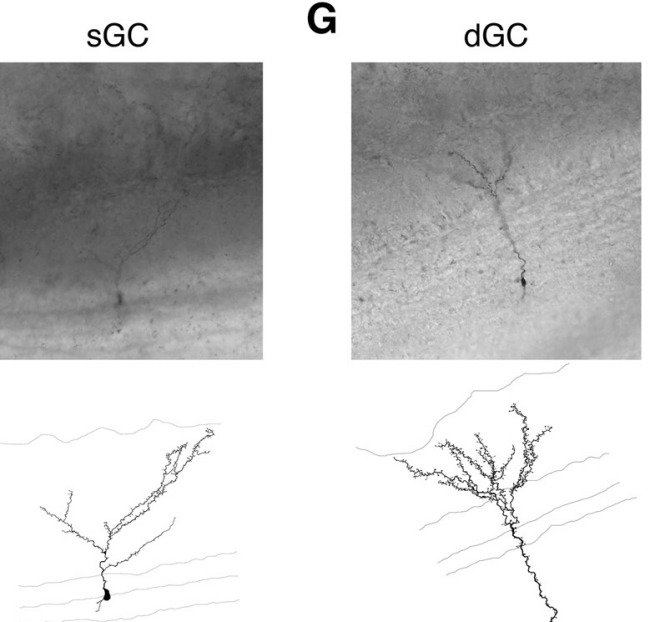

H
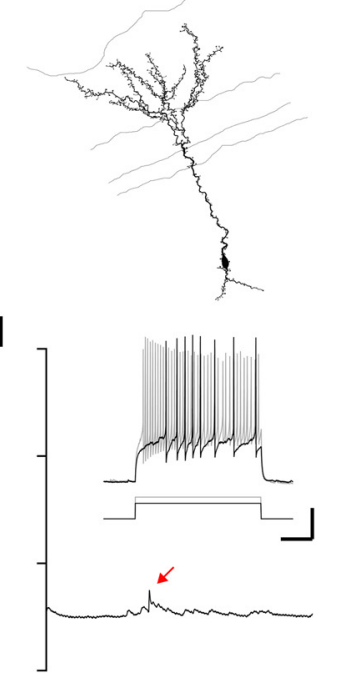

but was monitored continuously to ensure adequate electrode access and recording quality. Gabazine (GBZ; Tocris Bioscience) was applied transiently for 1-3 min at proximal somatodendritic or distal apical dendritic domains of GCs using a patch pipette filled with Ringer's solution, $100 \mu \mathrm{M} \mathrm{GBZ}$, and $25 \mu \mathrm{M}$ Alexa Fluor 488 to visually monitor drug diffusion. Data collection began $<10 \mathrm{~s}$ after the onset of GBZ application.

OSN stimulation. For extracellular stimulation, a monopolar glass electrode was filled with Ringer's solution and connected to a stimulus isolation unit (World Precision Instruments) controlled by transistor-transistor logic pulses from the ITC-18 acquisition board. To selectively activate OSN axons within a single glomerular microcircuit, the stimulation electrode was positioned within the olfactory nerve layer (ONL) slightly superficial and rostral to the target glomerulus, often targeting a visible OSN fiber bundle, as described previously (Borisovska et al., 2011; Najac et al., 2011; Gire et al., 2012). Glomeruli were targeted based on their visibility and proximity to the recorded cell (typically positioned directly superior to the recorded cell). The intensity of extracellular stimulation (100- $\mu$ s-long pulses; $27.0 \pm 20.1 \mu \mathrm{A}, n=78$ ) was increased until excitatory synaptic input was observed reliably ( $\sim 95 \%$ success rate) on each trial in either GCs or dSACs. Increasing the stimulation intensity past the threshold level needed to reliably evoke synaptic excitation typically resulted in a negligible increase in synaptic excitation onto GCs (data not shown), consistent with the all-ornothing nature of glomerular long-lasting depolarizations (LLDs; Gire and Schoppa, 2009). Of note, identical methods were used previously to evoke LLDs in MCs/TCs and never resulted in direct excitation of MC/TC apical dendrites (Burton and Urban, 2014). For clarity, stimulus artifacts have been blanked in plots showing the response of cells to extracellular OSN stimulation, except when noted. For optogenetic stimulation, slices were illuminated (10-20 ms light pulse) by a $75 \mathrm{~W}$ xenon arc lamp passed through a YFP filter set and $60 \times$ water-immersion objective centered on a single glomerulus with either

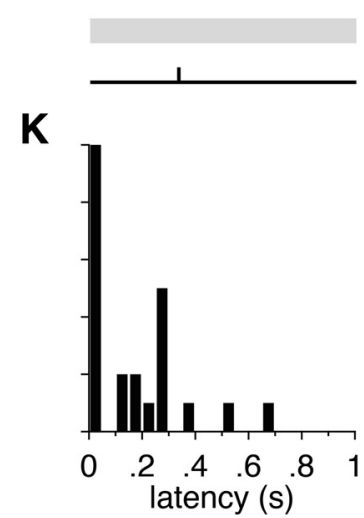

Figure 1. Glomerular activation drives asynchronous subthreshold and suprathreshold excitation of GCs. A, Circuitry of the MOB. Excitatory cell classes are shown in black. Inhibitory cell classes targeting excitatory cells are shown in red. Inhibitory cell classes targeting other inhibitory cells are shown in blue. GL, Glomerular layer; IPL, internal plexiform layer; ETC, external tufted cell; PGC, periglomerular cell; SSAC, superficial short-axon cell; EPL-IN, EPL-interneuron; GL-dSAC, GL-projecting dSAC; EPL-dSAC, EPL-projecting dSAC; GCL-dSAC, GCL-projecting dSAC; IBP, intrabulbar projection; LOT, lateral olfactory tract. $\boldsymbol{B}$, Experimental design. GC activity was monitored using whole-cell patch-clamp recordings while single glomeruli were activated by low-level $\leftarrow$

stimulation of OSN axons. C, Bright-field image (top; scale bar, $100 \mu \mathrm{m}$ ) and morphological reconstruction (bottom) of a representative $S G C$. Gray lines in this and all subsequent reconstructions correspond to the cell layers labeled in A. M, Medial; $P$, posterior. $\boldsymbol{D}$, Representative voltage trace (top) and raster plot of spike times across multiple trials (middle) after a single OSN stimulation pulse (bottom) for the SGC shown in C. The highlighted trial in this and all subsequent raster plots corresponds to the representative trace shown. Red arrow marks a spontaneous spikelet. $\boldsymbol{E}, \boldsymbol{F}$, Same as $\boldsymbol{C}$ and $\boldsymbol{D}$ for another sGC showing a barrage of asynchronous EPSPs and unreliable, long-latency firing. $\boldsymbol{G}, \boldsymbol{H}$, Same as $\mathbf{C}$ and $\boldsymbol{D}$ for a representative dGC showing subthreshold excitation and spikelets (inset: suprathreshold response to step current injections; calibration: $0.5 \mathrm{~s}, 20 \mathrm{mV} / 100 \mathrm{pA}) . I$, Histogram of mean spike probabilities across all trials. Note that several GCs exhibit only subthreshold responses. J, $\boldsymbol{K}$, Histograms of mean number of spikes evoked $(\boldsymbol{J})$ and mean first-spike latencies $(\boldsymbol{K})$ per suprathreshold trial. 
Table 1. Passive membrane properties

\begin{tabular}{lcc}
\hline & $\mathrm{GC}$ & $\mathrm{dSAC}$ \\
\hline$R_{\text {input }}(\mathrm{M} \Omega)$ & $603.2 \pm 363.4(32)$ & $273.4 \pm 129.5(10)^{*}$ \\
$\tau_{\mathrm{m}}(\mathrm{ms})$ & $27.3 \pm 13.2(28)$ & $13.0 \pm 5.6(9)^{*}$ \\
$C_{\mathrm{m}}(\mathrm{pF})$ & $46.1 \pm 11.7(28)$ & $49.5 \pm 17.1(9)$ \\
$V_{\text {rest }}(\mathrm{mV})$ & $-71.2 \pm 8.5(40)$ & $-65.9 \pm 7.5(10)$ \\
\hline${ }^{*} p<0.01$ (two-tailed unpaired $t$ test). Values reported are mean $\pm S D(n)$. &
\end{tabular}

Table 2. Action potential properties

\begin{tabular}{lrr}
\hline & \multicolumn{1}{c}{ GC } & \multicolumn{1}{c}{ dSAC } \\
\hline$V_{\text {threshold }}(\mathrm{mV})$ & $-28.9 \pm 7.8(31)$ & $-46.0 \pm 7.5(9)^{*}$ \\
Amplitude $(\mathrm{mV})$ & $55.2 \pm 12.0(31)$ & $72.7 \pm 9.9(9)^{*}$ \\
FWHM (ms) & $1.00 \pm 0.19(31)$ & $0.73 \pm 0.17(9)^{*}$ \\
Rising slope (mV/ms) & $167.8 \pm 64.3(31)$ & $272.3 \pm 83.3(9)^{*}$ \\
Falling slope (mV/ms) & $-60.3 \pm 13.9(31)$ & $-102.5 \pm 29.5(9)^{*}$
\end{tabular}

${ }^{*} p<0.001$ (two-tailed unpaired $t$ test). Values reported are mean \pm SD $(n)$.

Table 3. Spike train properties

\begin{tabular}{lcc}
\hline & GC & dSAC \\
\hline Rheobase (pA) & $37.1 \pm 21.2(31)$ & $42.8 \pm 24.6(9)$ \\
Rheobase first-spike latency (ms) & $511.6 \pm 529.6(31)$ & $182.5 \pm 184.3(9)$ \\
Gain (Hz/pA) & $0.86 \pm 0.33(30)$ & $0.41 \pm 0.18(9)^{*}$ \\
Peak instantaneous rate (Hz) & $53.2 \pm 21.7(31)$ & $112.3 \pm 64.8(9)^{*}$
\end{tabular}

${ }^{*} p<0.001$ (two-tailed unpaired $t$ test). Values reported are mean $\pm S D(n)$.

closed or open field stop, achieving uniglomerular or multiglomerular activation in OMP-ChR2 mice, respectively. In TC recordings, "on-beam" describes photostimulation of the glomerulus to which the TC sends its apical dendrite, whereas "off-beam" describes photostimulation of the glomerulus just rostral to the on-beam glomerulus (see Fig. 6A).

Data analysis. Action potentials were detected with a voltage derivative threshold of $20 \mathrm{mV} / \mathrm{ms}$. Spikelets were detected with a voltage derivative threshold of $0.6 \mathrm{mV} / \mathrm{ms}$, minimum amplitude of $7 \mathrm{mV}$, and temporally separated from full somatic action potentials by $\geq 10 \mathrm{~ms}$, consistent with previous studies (Zelles et al., 2006; Labarrera et al., 2013) and providing a conservative estimate of spikelet prevalence that discounts numerous "prespikes" triggering full somatic action potentials (Zelles et al., 2006). Intrinsic biophysical properties (including passive membrane, action potential, and spike train properties) were measured as described previously (Burton and Urban, 2014). Postsynaptic events were detected using a standard template-matching function in Axograph (Clements and Bekkers, 1997). IPSCs in GCs were detected using a 51-ms-long doubleexponential template with $1 \mathrm{~ms}$ baseline, $2 \mathrm{~ms}$ rise time constant, and 10 $\mathrm{ms}$ decay time constant, approximately matching the kinetics of IPSCs observed previously in adult-born GCs (Carleton et al., 2003). EPSCs in GCs were detected using a 20-ms-long double-exponential template with $1 \mathrm{~ms}$ baseline, $0.5 \mathrm{~ms}$ rise time constant, and $4 \mathrm{~ms}$ decay time constant, approximately matching the kinetics of EPSCs observed previously (Schoppa, 2006a). All events were detected with a threshold amplitude of twice the SD of the baseline noise. Spurious event detections with rise times $>5 \mathrm{~ms}$, decay constants $>100 \mathrm{~ms}$ or $<2 \mathrm{~ms}$, or amplitudes $<6.5 \mathrm{pA}$ were excluded from analysis. Peristimulus time histograms (PSTHs) of EPSCs and IPSCs were calculated with a bin width of $10 \mathrm{~ms}$. Feedforward inhibition was considered statistically significant if the probability of observing an IPSC within $500 \mathrm{~ms}$ after OSN stimulation exceeded the $95 \%$ confidence interval of the probability of observing an IPSC within $500 \mathrm{~ms}$ before OSN stimulation. The latency and amplitude of feedforward inhibition in each cell was then calculated as the mean first IPSC latency and amplitude, respectively, in the first $10 \mathrm{~ms}$ time bin showing a significant increase in IPSC probability after OSN stimulation. Overall, this provided a conservative measure of feedforward inhibition requiring accurate matching of event waveforms to a single double-exponential IPSC template. In a small subset of GCs $(n=4)$, feedforward inhibition was clearly visible as a reliable upward current deflection after OSN stimulation but was not matched reliably to the IPSC template because of
Table 4. Spontaneous GC synaptic properties

\begin{tabular}{lcc}
\hline & \multicolumn{1}{c}{ sEPSC } & \multicolumn{1}{c}{ sIPSC } \\
\hline Frequency (Hz) & $4.1 \pm 4.3(37)$ & $1.5 \pm 1.3(37)$ \\
Amplitude $(\mathrm{pA})_{\text {Rise }_{10-90 \%}(\mathrm{~ms})}$ & $-17.0 \pm 7.1(37)$ & $24.9 \pm 10.5(37)$ \\
$\tau_{\text {decay }}(\mathrm{ms})$ & $1.0 \pm 0.3(37)$ & $1.5 \pm 0.7(37)$ \\
\hline
\end{tabular}

Values reported are mean \pm SD $(n)$.

strong coincident excitatory input and incomplete voltage clamp. This subset of GCs was excluded from our analyses of feedforward inhibition. The highly asynchronous nature of synaptic excitation onto GCs after OSN stimulation precluded accurate matching of all excitatory event waveforms to the single double-exponential EPSC template. Therefore, we calculated the excitation latency within each GC as the time from OSN stimulation to the first point that the mean excitation waveform deviated beyond the root-mean-squared noise level. All measurements are provided as mean $\pm S D$, unless noted otherwise. Error bars denote SEM, unless noted otherwise.

Simulations. GC simulations were performed in the NEURON simulation environment (Hines and Carnevale, 1997) with a time step of $10 \mu \mathrm{s}$ (a time step of $1 \mu$ s yielded equivalent results in a subset of simulations tested). The model GC was reproduced from previously published work (Li and Cleland, 2013) and consisted of four compartments (soma, apical dendrite, gemmule/spine neck, and gemmule/spine body) with multiple experimentally derived biophysical conductances (see Fig. 8A; Li and Cleland, 2013). Excitatory synaptic inputs consisted of the following: (1) an AMPAR-like conductance with a reversal potential of $0 \mathrm{mV}$, rise time constant of $1.0 \mathrm{~ms}$, and decay time constant of $7.1 \mathrm{~ms}$, matching the average spontaneous EPSC (sEPSC) kinetics observed (Table 4); and (2) an NMDAR-like conductance with a reversal potential of $0 \mathrm{mV}$, rise time constant of $3.18 \mathrm{~ms}$, decay time constants of 57.14 and $2000 \mathrm{~ms}$, and physiological $\mathrm{Ca}^{2+}$ permeability (reproduced from Grunditz et al., 2008) calculated using a spine head surface area of $3.71 \mu \mathrm{m}^{2}$ (Woolf et al., 1991a). Feedforward inhibitory synaptic inputs consisted of a GABA $\mathrm{A}$ like conductance with a reversal potential of $-78.9 \mathrm{mV}$ (Pressler and Strowbridge, 2006), rise time constant of $1.5 \mathrm{~ms}$, and decay time constant of $19.7 \mathrm{~ms}$, matching the average sIPSC kinetics observed (Table 4). The maximum excitatory conductance ( $\left.g_{\mathrm{ex}} \mathrm{max}\right)$ for AMPAR- and NMDARlike inputs was set to 2 and $1 \mathrm{nS}$, respectively, paralleling previous MOB modeling studies (Migliore et al., 2010, 2014; Li and Cleland, 2013; Yu et al., 2013,2014). The maximum inhibitory conductance was set to $2 \mathrm{nS}$ to match the largest feedforward inhibitory events that we observed (in which our voltage clamp was likely to be the most complete). Trial-totrial spike-time reliability for suprathreshold trials was calculated as described previously (Schreiber et al., 2003), using a Gaussian kernel with 2 ms SD.

\section{Results}

Physiological activation of olfactory bulb glomeruli drives asynchronous subthreshold and suprathreshold excitation of GCs in vitro

Sensory input to the MOB is organized by odorant receptors into distinct glomeruli (Ressler et al., 1994; Vassar et al., 1994; Mombaerts et al., 1996). Each glomerulus is a large microcircuit in which diverse excitatory and inhibitory interneurons modulate the sensory-evoked excitation of principal MC/TC apical dendrites by OSN afferent terminals (for review, see Wachowiak and Shipley, 2006; Cleland, 2010; Nagayama et al., 2014). Several recent studies have demonstrated that odor presentation in vivo or transient OSN stimulation in vitro triggers complex interactions within the glomerulus that generate rapid TC firing but delayed MC firing (De Saint Jan et al., 2009; Najac et al., 2011; Fukunaga et al., 2012, 2014; Gire et al., 2012; Igarashi et al., 2012; Burton and Urban, 2014). To begin to investigate the synaptic basis of GC recruitment, we first characterized the response of GCs to transient low-level stimulation of OSNs that recapitulates the 
physiological temporal cascade of MC/TC firing within a single glomerular microcircuit (Fig. 1B; see Materials and Methods).

GCs responded to OSN stimulation with a broad range of activity patterns, including reliable short-latency firing (Fig. $1 C, D$ ), unreliable long-latency firing (Fig. $1 E, F$ ), and asynchronous subthreshold depolarizations (Fig. 1G,H). Subthreshold responses were not attributable to an inability to fire action potentials, because all GCs exhibited normal firing in response to step current injections (Fig. 1H; Tables 2, 3). In addition, many GCs (at least 16 of 35, given our conservative estimates; see Materials and Methods) also exhibited evoked (Fig. 1H) and/or spontaneous (Fig. 1D) spikelets, although few GCs (3 of 35) fired full spontaneous action potentials. These spikelets resemble strongly the dendritic branch-specific $\mathrm{Na}^{+}$-dependent action potentials (Pinato and Midtgaard, 2005; Zelles et al., 2006) that have been observed frequently in mammalian GCs in vivo (Mori and Takagi, 1978; Wellis and Scott, 1990; Luo and Katz, 2001; Labarrera et al., 2013) but have thus far been unreported in mammalian GCs in vitro. Such dendritic branch-specific activity is likely to play a critical role in olfactory processing by regulating the subcellular release of GABA from GC dendrites onto select MC/TC populations (Zelles et al., 2006; see Discussion). In total, the broad range of activity patterns observed (Fig. $1 I-K$ ) is distinct from previous in vitro accounts that examined GC responses to synchronous MC/TC activation (Egger et al., 2005) but is identical to the broad range of odor-evoked GC activity patterns observed in vivo (Wellis and Scott, 1990; Luo and Katz, 2001; Cang and Isaacson, 2003; Margrie and Schaefer, 2003; Labarrera et al., 2013; Cazakoff et al., 2014; Fukunaga et al., 2014). Collectively, the close correspondence between our results and the odorevoked GC activity observed previously in vivo suggests strongly that the asynchronous MC/TC firing generated by glomerular microcircuit interactions critically regulates odor-evoked GC activity. Having thus established the recruitment properties of GCs in vitro, we next examined the synaptic integration underlying GC recruitment.

\section{GCs receive asynchronous synaptic excitation and synchronous synaptic inhibition}

Odors can trigger both synaptic excitation (Wellis and Scott, 1990; Luo and Katz, 2001; Cang and Isaacson, 2003; Margrie and Schaefer, 2003; Fukunaga et al., 2014) and inhibition (Labarrera et al., 2013) onto GCs in vivo. GC recruitment by sensory input to the MOB should thus reflect the integration of both excitatory and inhibitory input. Although considerable research has focused on dendrodendritic excitation of GCs (for review, see Schoppa and Urban, 2003; Egger and Urban, 2006), relatively little is known about inhibition of GCs. Synaptic inhibition onto GCs can arise from both dSACs intrinsic to the MOB (Pressler and Strowbridge, 2006; Eyre et al., 2008; Boyd et al., 2012) and extrinsic centrifugal innervation (Nunez-Parra et al., 2013), and artificial activation of either of these pathways (by tetanic GCL stimulation or optogenetic photostimulation, respectively) can dramatically reduce the firing of GCs in response to somatic step current injections. Whether odors trigger synaptic inhibition onto GCs through a top-down centrifugal mechanism or through a feedforward mechanism intrinsic to the MOB is not known. Furthermore, the temporal structure of sensory-evoked inhibition onto GCs and the influence of inhibition on GC spike timing have not been characterized. Finally, it is unclear how robust synaptic inhibition onto GCs is, given the following:
(1) inhibition onto GCs in vitro has only been observed previously with tetanic GCL stimulation (Pressler and Strowbridge, 2006) or in a small fraction of GCs using repetitive ONL stimulation (Schoppa, 2006a; see Discussion); and (2) inhibition onto GCs in vivo was detected reliably in only a handful of GC-odor pairs (Labarrera et al., 2013; see Discussion).

Thus, to examine the synaptic basis of GC recruitment after physiological activation of a single glomerulus, we repeated the previous experiment (Fig. 1B) while sequentially clamping GCs at the reversal potentials of synaptic inhibition and excitation, respectively (Fig. 2). Low-level stimulation of OSNs triggered highly asynchronous barrages of EPSCs in both sGCs (Fig. $2 B, C$ ) and dGCs (Fig. $2 I, J)$, beginning $6.3 \pm 7.5 \mathrm{~ms}(n=37)$ after OSN stimulation and lasting several hundred milliseconds on average (Fig. $2 D, K$ ), consistent with the repetitive firing and distributed spike latencies observed in MCs/TCs (Burton and Urban, 2014). Of note, this asynchronous excitatory drive can combine with long-lasting currents mediated by metabotropic glutamate receptors (Heinbockel et al., 2007a,b), canonical transient receptor potential channels (Hall and Delaney, 2002; Egger, 2008; Stroh et al., 2012), and NMDARs (Schoppa et al., 1998) in unclamped GCs to support prolonged depolarizations and long-latency firing, consistent with our above results (Fig. 1).

Strikingly, clamping GCs at the reversal potential of synaptic excitation revealed robust and reliable synaptic inhibition onto both sGCs (Fig. $2 E, F$ ) and dGCs (Fig. $2 L, M$ ), with a mean firstIPSC amplitude after OSN stimulation of $56.4 \pm 56.4 \mathrm{pA}(n=$ 32). Inhibition onto GCs was highly prevalent, with a significant increase in the probability of observing an IPSC after OSN stimulation observed in 32 of 33 total GCs recorded. In strong contrast to the asynchronous excitatory input to GCs, inhibitory input to GCs was highly synchronous (Fig. 2G,N), typically consisting of one to two IPSCs. Furthermore, inhibition onto GCs was rapid, with a mean onset of $13.3 \pm 9.7 \mathrm{~ms}$, suggesting strongly that a synaptic pathway intrinsic to the MOB mediates inhibition onto GCs. Indeed, inhibition followed the onset of excitation with a mean lag of $6.9 \pm 7.0 \mathrm{~ms}(n=32)$, consistent with a canonical monosynaptic excitation and disynaptic feedforward inhibition circuit. Given the high prevalence and polysynaptic nature of this inhibition and the inevitable disruption of some synaptic connections during the slicing procedure, our results thus collectively demonstrate for the first time that essentially all GCs receive reliable, short-latency, and synchronous synaptic inhibition after glomerular activation.

Repetitive sniffing dynamically modulates the strength of sensory input to the MOB in the behaving animal (for review, see Wachowiak, 2011). Thus, to evaluate the relevance of synaptic inhibition onto GCs in a more physiological context, we additionally examined whether the observed synaptic inhibition onto GCs is reliably evoked by patterned OSN stimulation mimicking theta frequency sniffing. Indeed, short-latency inhibition was reliably and synchronously evoked onto GCs by each of five $4 \mathrm{~Hz}$ OSN stimulation pulses (Fig. $3 E$ ), yielding robust and highly phasic increases in IPSC probabilities (Fig. $3 F, G$ ). In contrast, $4 \mathrm{~Hz}$ OSN stimulation evoked highly asynchronous synaptic excitation onto GCs (Fig. 3B), with uniformly elevated EPSC probabilities throughout the entire stimulation train (Fig. $3 C, D$ ). Synchronous synaptic inhibition onto GCs is thus not only robust and reliable in the acute slice preparation but also likely plays a critical role in regulating GC recruitment during olfactoryguided behavior. 

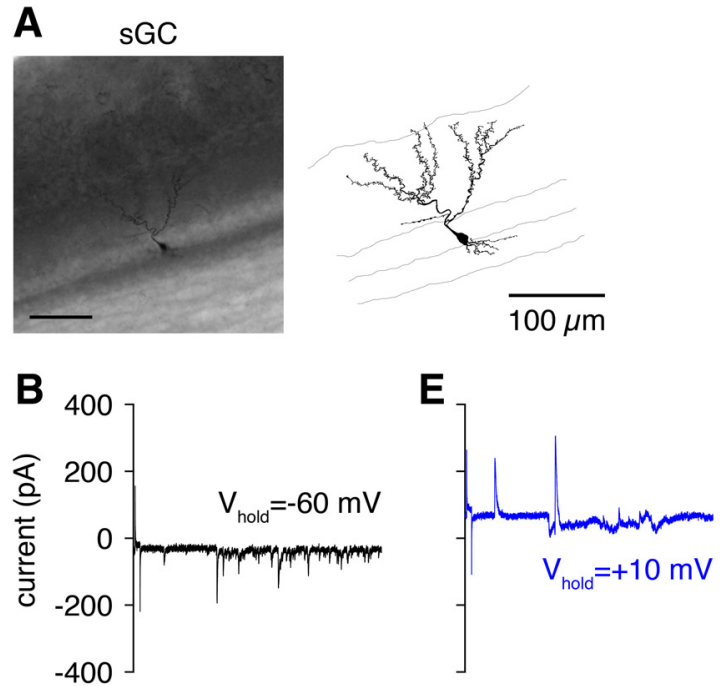

| | || ||| || || || ||||| || ||| |||||||||||

| | | |||||| ||||||||||| ||| ||||||||

|| | ||||||||||||||||||| ||||||||||| |||

| | || |||||||||| ||||||||||| | |

|| | | ||||| ||| ||||||||| | ||||||| |

|| || || | ||||| ||||| ||| | || ||| || ||
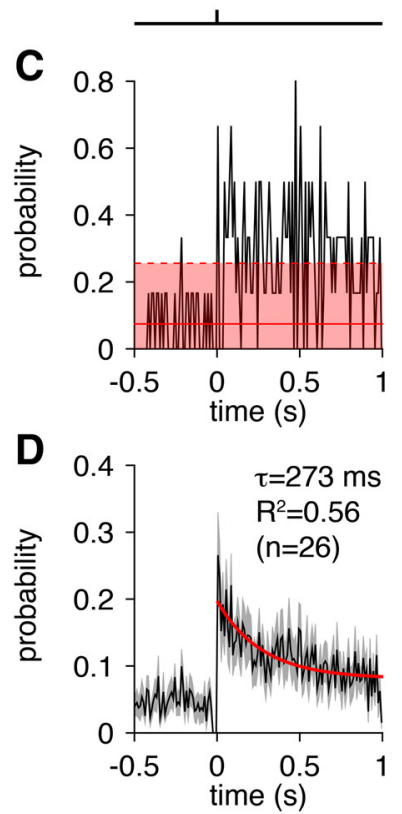
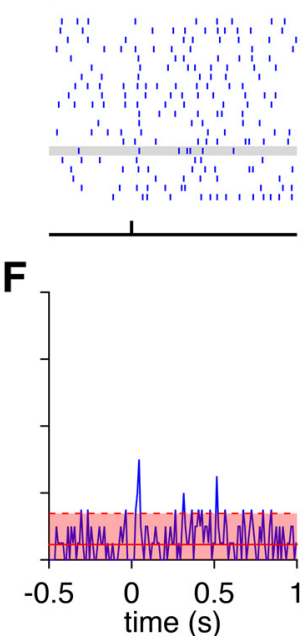

G

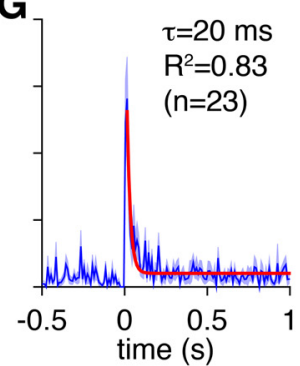

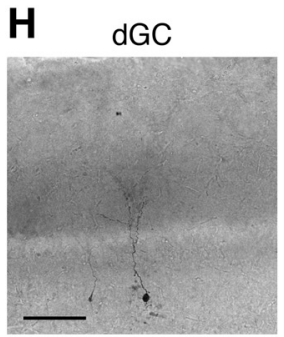
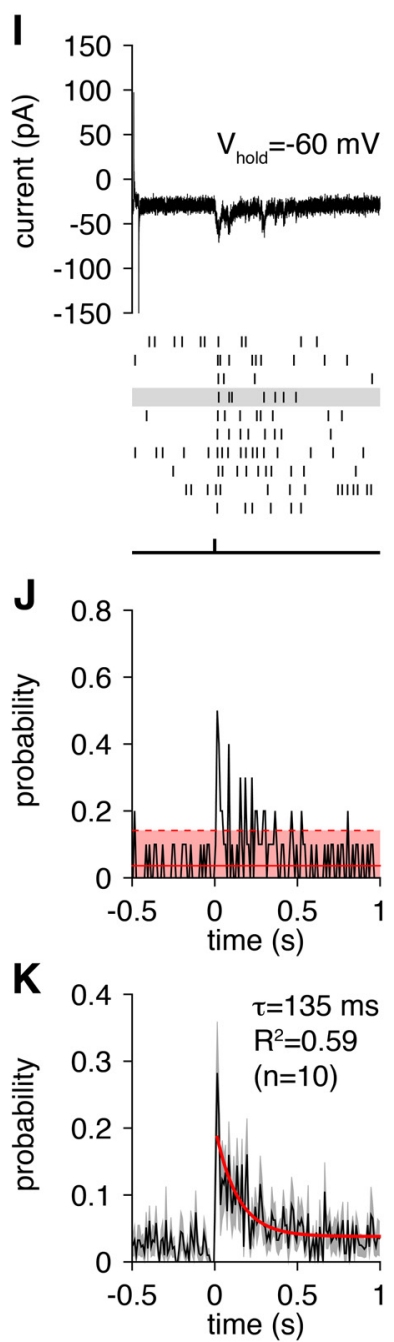

$\mathbf{L}$
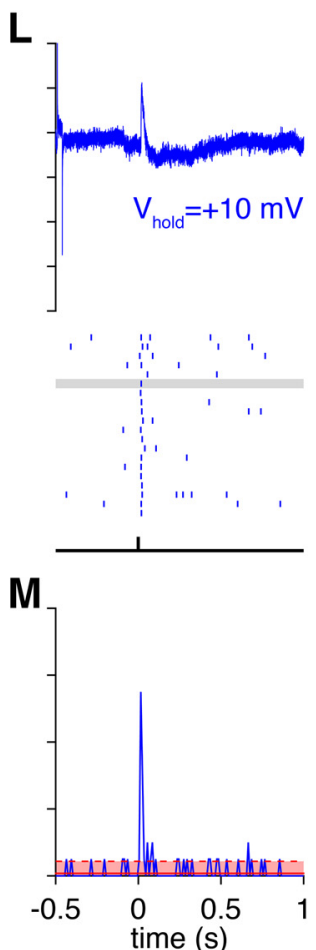

N

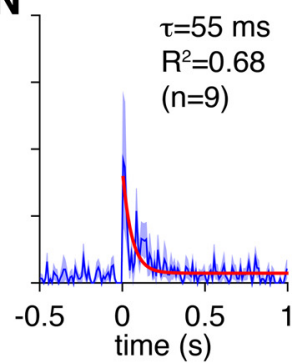

Figure 2. GCs integrate asynchronous synaptic excitation and synchronous synaptic inhibition. $A$, Bright-field image (left; scale bar, $100 \mu \mathrm{m}$ ) and morphological reconstruction (right) of a representative SGC. $\boldsymbol{B}$, Representative excitatory current trace (top) and raster plot of EPSC times across multiple trials (middle) after a single 0SN stimulation pulse (bottom) for the GC shown in $\boldsymbol{A}$. C, PSTH of EPSC times plotted in $\boldsymbol{B}$. Solid and dashed red lines and coloring show the mean and $95 \%$ confidence interval, respectively, of the EPSC probability 500 ms before 0 SN stimulation. $\boldsymbol{D}$, Mean PSTH of EPSC times across sGCs. Shading denotes mean \pm SEM. Red line shows a single-exponential fit. $\boldsymbol{E}-\mathbf{G}$, Same as $\boldsymbol{B}-\boldsymbol{D}$ for synaptic inhibition onto sGCs. $\boldsymbol{H}-\boldsymbol{N}$, Same as $\boldsymbol{A}-\boldsymbol{G}$ for dGCs.

dSACs mediate feedforward inhibition onto proximal somatodendritic and distal apical dendritic domains of GCs The rapid timescale and robust nature of the inhibition evoked onto GCs by OSN stimulation suggests strongly that interneurons intrinsic to the MOB mediate feedforward synaptic inhibition onto GCs. dSACs are the only known class of MOB interneurons that monosynaptically inhibit GCs (Pressler and Strowbridge, 2006; Eyre et al., 2008; see Discussion). Thus, we hypothesized that glomerular activation recruits dSACs to mediate the observed synaptic inhibition onto GCs. Of note, this model requires that physiological activation of a single glomerulus recruits $\mathrm{dSAC}$ firing that is consistent with the rapid and reliable nature of the observed inhibition onto GCs (Fig. 2). However, at present, dSAC recruitment has only been examined using direct glomerular stimulation in a subset of dSACs termed "Blanes cells" held at depolarized potentials perithreshold for firing (Pressler and Strowbridge, 2006). Therefore, to test our hypothesis, we next characterized the response of dSACs at resting membrane potentials (Table 1) to transient low-level stimulation of OSNs (Fig. 4A).

Consistent with our hypothesis, dSACs with axons arborizing across the EPL and bearing clear bouton-like structures (Fig. 4B,D) exhibited rapid and highly reliable first-spike latencies after transient OSN stimulation (Fig. 4C,E). Similar activity was likewise observed 

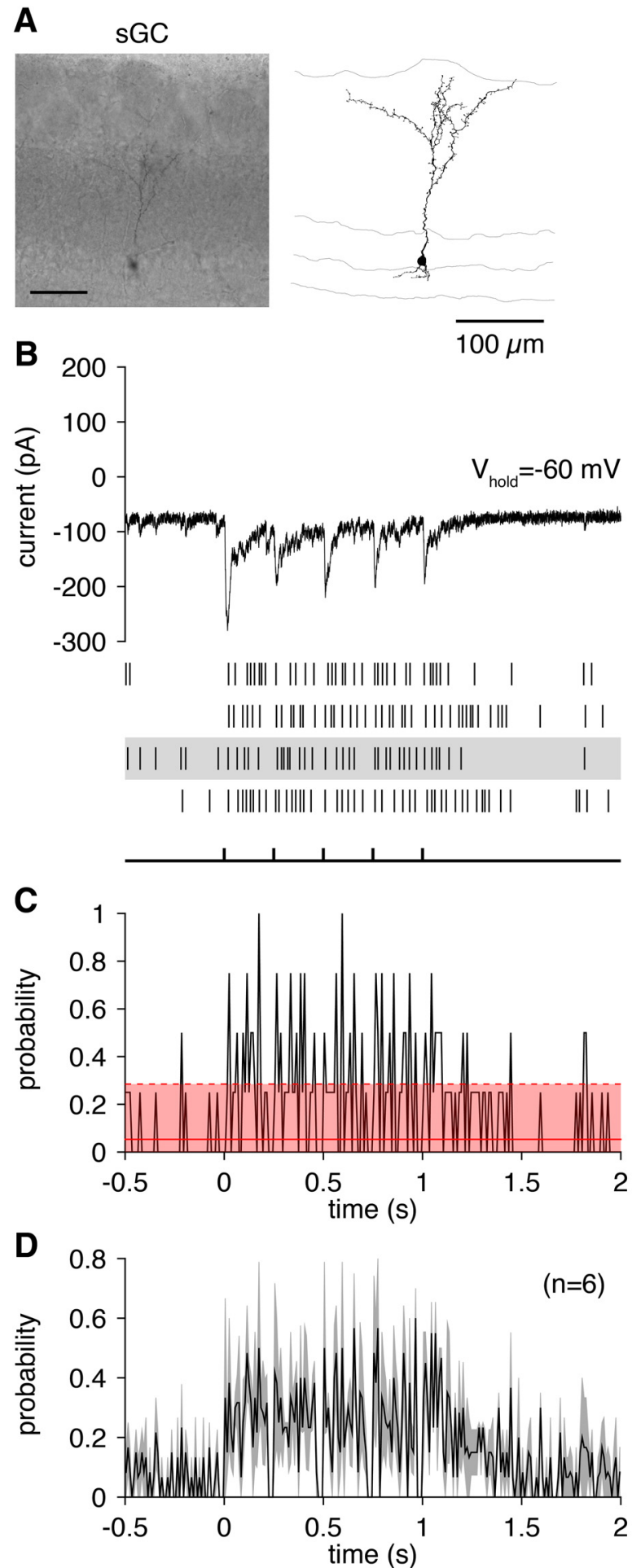
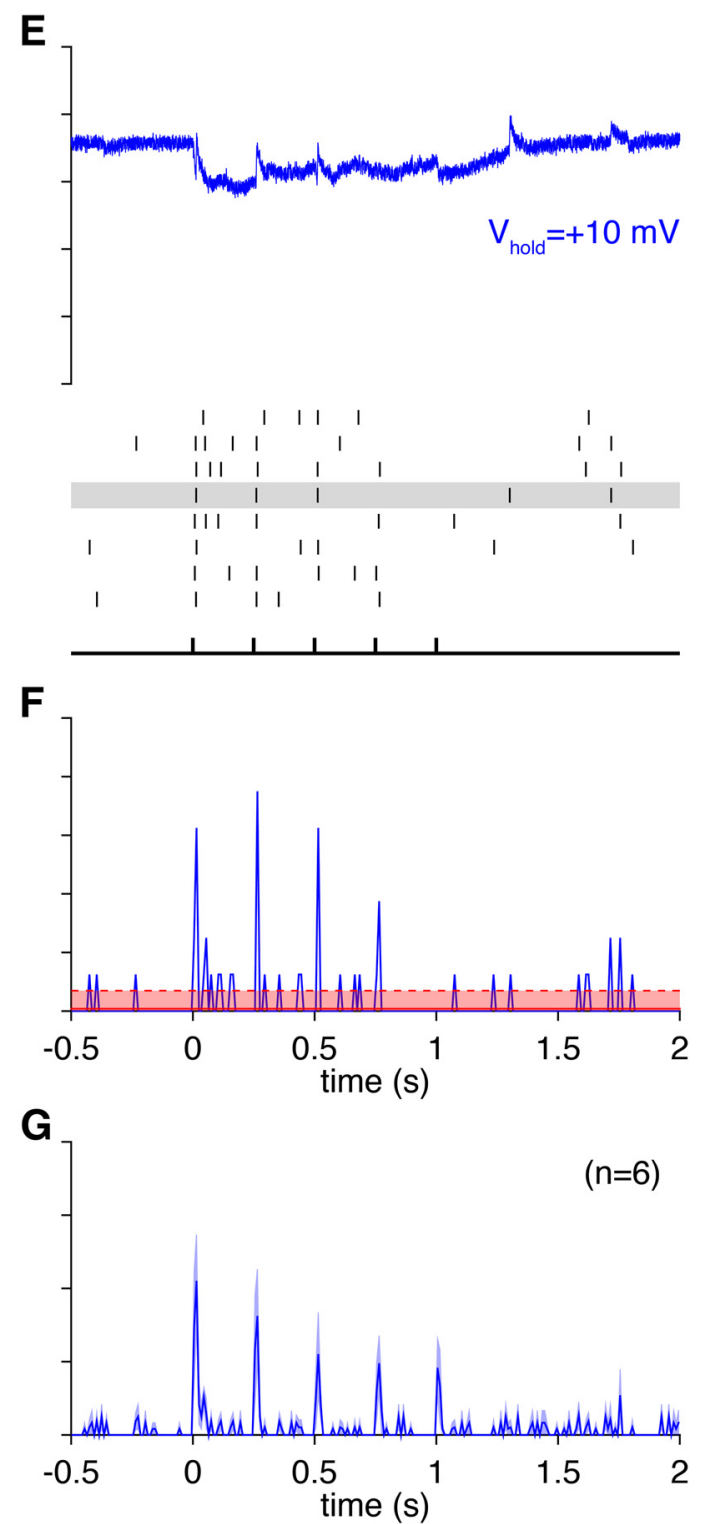

Figure 3. Synaptic inhibition onto GCs is reliable across physiological theta frequency sniff rhythms. $\boldsymbol{A}$, Bright-field image (left; $s c a l e$ bar, $100 \mu \mathrm{m}$ ) and morphological reconstruction (right) of a representative $S G C$. $B$, Representative excitatory current trace (top) and raster plot of EPSC times across multiple trials (middle) after five 0SN stimulation pulses at $4 \mathrm{~Hz}$ (bottom) for the $\mathrm{GC}$ shown in $\boldsymbol{A}$. C, PSTH of EPSC times plotted in $\boldsymbol{B}$. Solid and dashed red lines and coloring show the mean and $95 \%$ confidence interval, respectively, of the EPSC probability 500 ms before the first 0 SN stimulation pulse. $\boldsymbol{D}$, Mean PSTH of EPSC times across GCS. Shading denotes mean \pm SEM. $\boldsymbol{E}-\boldsymbol{G}$, Same as $\boldsymbol{B}-\boldsymbol{D}$ for synaptic inhibition onto GCS.

in a subset of glomerular layer (GL)-projecting dSACs (Fig. 4F, G) known to form en passant synapses onto GCs in the EPL (Eyre et al., 2008). Critically, the first spike latency across all dSACs (16.4 \pm 11.2 ms, $n=10$ ) — including spiny Blanes cells (Fig. 4D) as well as other dSAC types (Price and Powell, 1970b; Pressler and Strowbridge, 2006; Eyre et al., 2008; Pressler et al., 2013; Fig. 4B,F)—coincided with the onset of the observed synaptic inhibition onto GCs (Fig. $4 H$ ), supporting strongly the hypothesis that dSACs mediate rapid feedforward inhibition onto GCs. Interestingly, dSAC first-spike latencies consistently followed TC first-spike latencies but preceded $\mathrm{MC}$ first-spike latencies recorded under equivalent conditions (Fig. 4H; Burton and Urban, 2014). This temporal structure suggests that 
A

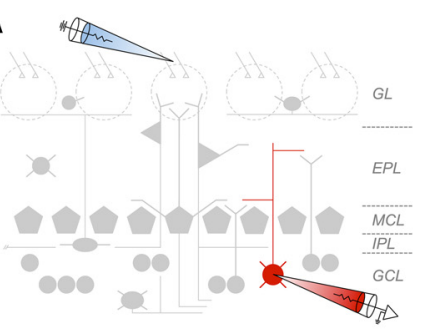

B
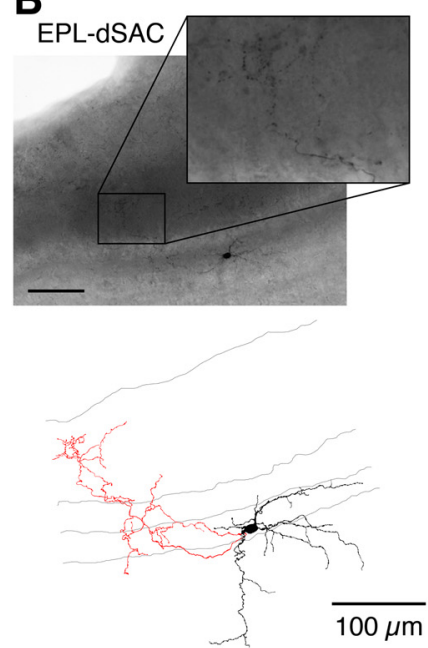

C

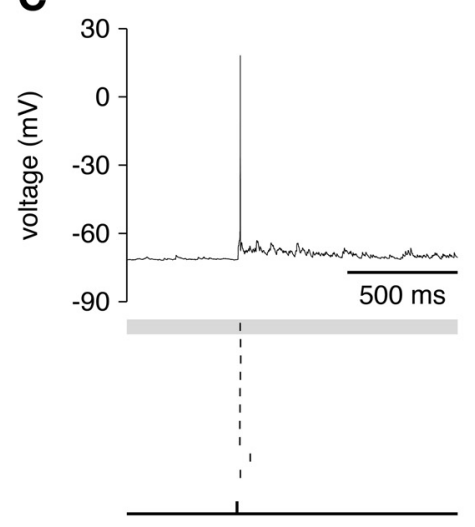

H
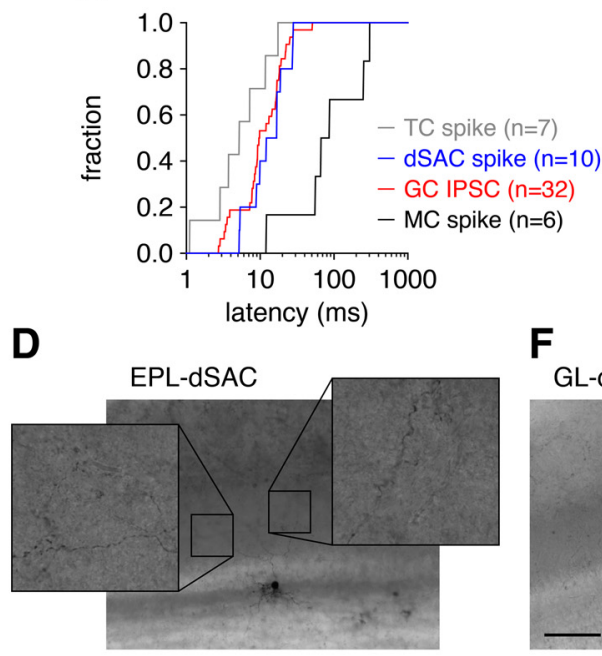

F
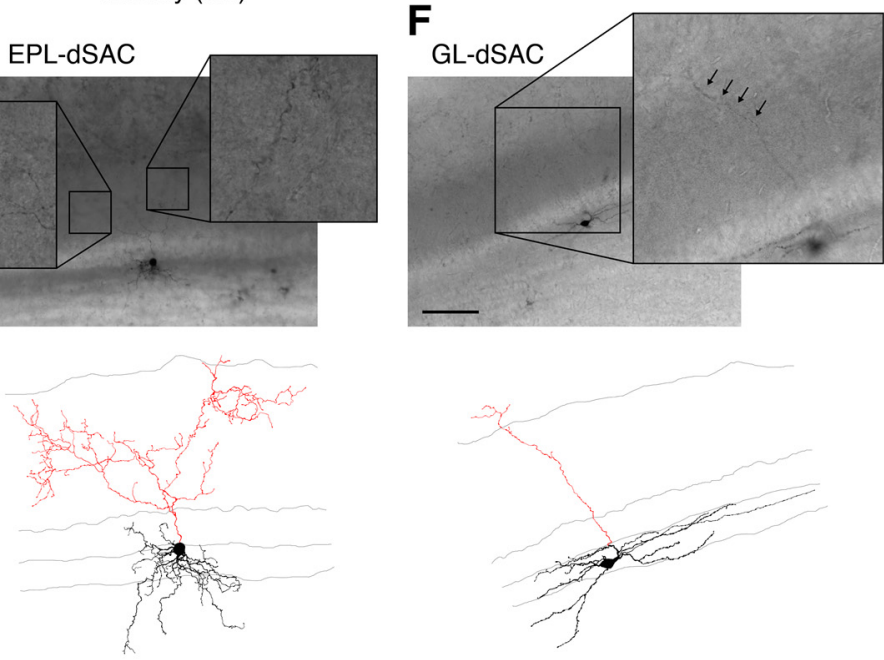

E

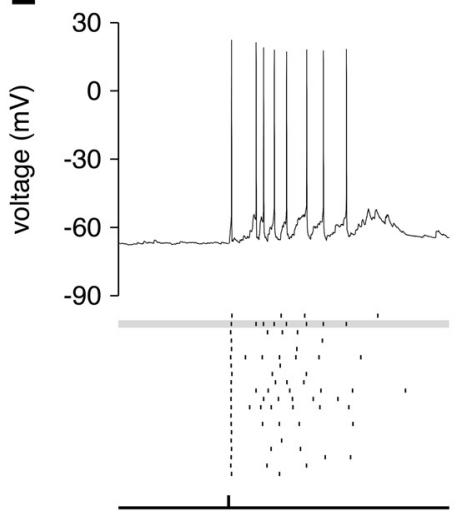

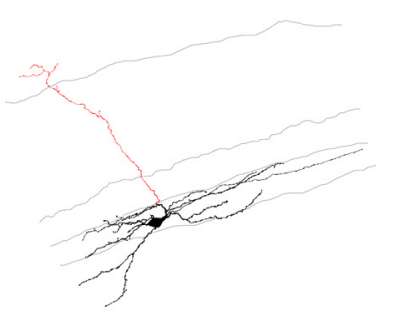

G

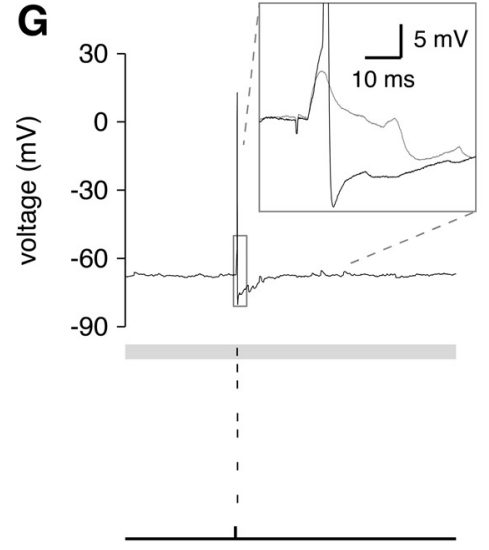

Figure 4. Glomerular activation drives reliable short-latency $\mathrm{dSAC}$ firing. $A$, Experimental design. $\mathrm{dSAC}$ activity was monitored using whole-cell patch-clamp recordings while single glomeruli were activated by low-level stimulation of OSN axons. B, Bright-field image (top; scale bar, $100 \mu \mathrm{m}$; inset: axonal boutons in the EPL) and morphological reconstruction (bottom; axon colored red) of a representative EPL-dSAC. C, Representative voltage trace (top) and raster plot of spike times across multiple trials (middle) after a single OSN stimulation pulse (bottom) for the EPL-dSAC shown in $\boldsymbol{B}$. Note the highly reliable short-latency firing after OSN stimulation. $\boldsymbol{D}-\boldsymbol{G}$, Same as $\boldsymbol{B}$ and $\boldsymbol{C}$ for a second EPL-dSAC $(\boldsymbol{D}, \boldsymbol{E})$ and a representative GL-dSAC $(\boldsymbol{F}, \boldsymbol{G})$. Inset, GL-dSAC firing (or depolarization on a subthreshold trial) followed OSN stimulation (note the stimulus artifact) with a nonzero latency, consistent with synaptic excitation and non-antidromic stimulation by the extracellular stimulation electrode positioned within the ONL. H, Cumulative distributions of the mean first-spike latencies of MCS/TCs (from Burton and Urban, 2014) and dSACs and the onset of inhibition onto GCs after OSN stimulation. IPL, Internal plexiform layer; EPL-dSAC, EPL-projecting dSAC; GCL-dSAC, GCL-projecting dSAC.

TCs (and/or external TCs, which likewise exhibit rapid recruitment; Gire et al., 2012) provide a strong source of synaptic excitation to EPL- and GL-projecting dSACs, consistent with the extensive overlap of EPL- and GL-projecting dSACs and TC axon collaterals in the internal plexiform layer and superficial GCL (Kishi et al., 1984; Orona et al., 1984; Liu and Shipley, 1994; Eyre et al., 2008).

Ultrastructural analyses have demonstrated that dSACs form GABAergic synapses onto both distal apical dendritic and proximal somatodendritic domains of GCs (Eyre et al., 2008). This suggests that the inhibitory synaptic currents recorded in GCs (Figs. 2, 3) reflect GABAergic inputs to either distal apical dendritic or proximal somatodendritic domains or both. Determining the subcellular localization of synaptic inhibition onto
GCs is of critical importance, given that dendritic inhibition could significantly attenuate dendritic $\mathrm{Ca}^{2+}$ influx (for review, see Higley, 2014) and GABA release onto MCs/TCs (for review, see Schoppa and Urban, 2003; Egger and Urban, 2006) and inhibit dendritic spike generation (Mori and Takagi, 1978; Wellis and Scott, 1990; Luo and Katz, 2001; Pinato and Midtgaard, 2005; Zelles et al., 2006; Labarrera et al., 2013; Fig. $1)$, whereas somatodendritic inhibition could inhibit the generation of full action potentials by dendritic spikes (Luo and Katz, 2001; Pinato and Midtgaard, 2005; Zelles et al., 2006; Simões-de-Souza et al., 2014) and attenuate GC excitation by centrifugal fibers (Balu et al., 2007) and MC/TC axon collaterals (Schoppa, 2006a). 
A

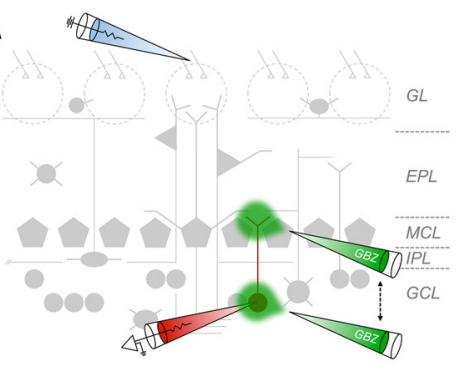

B
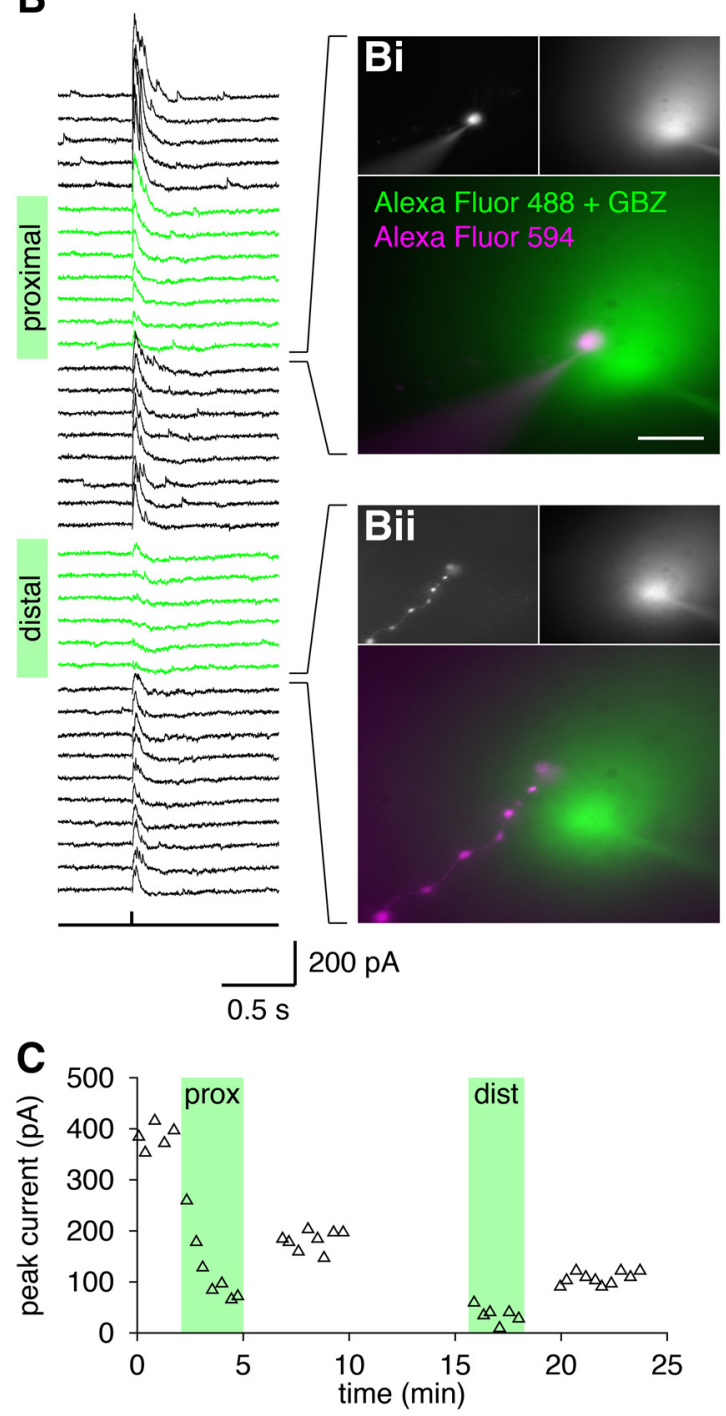

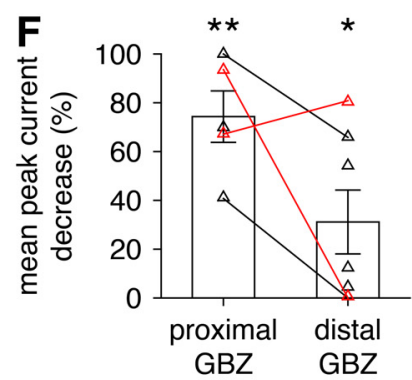

D
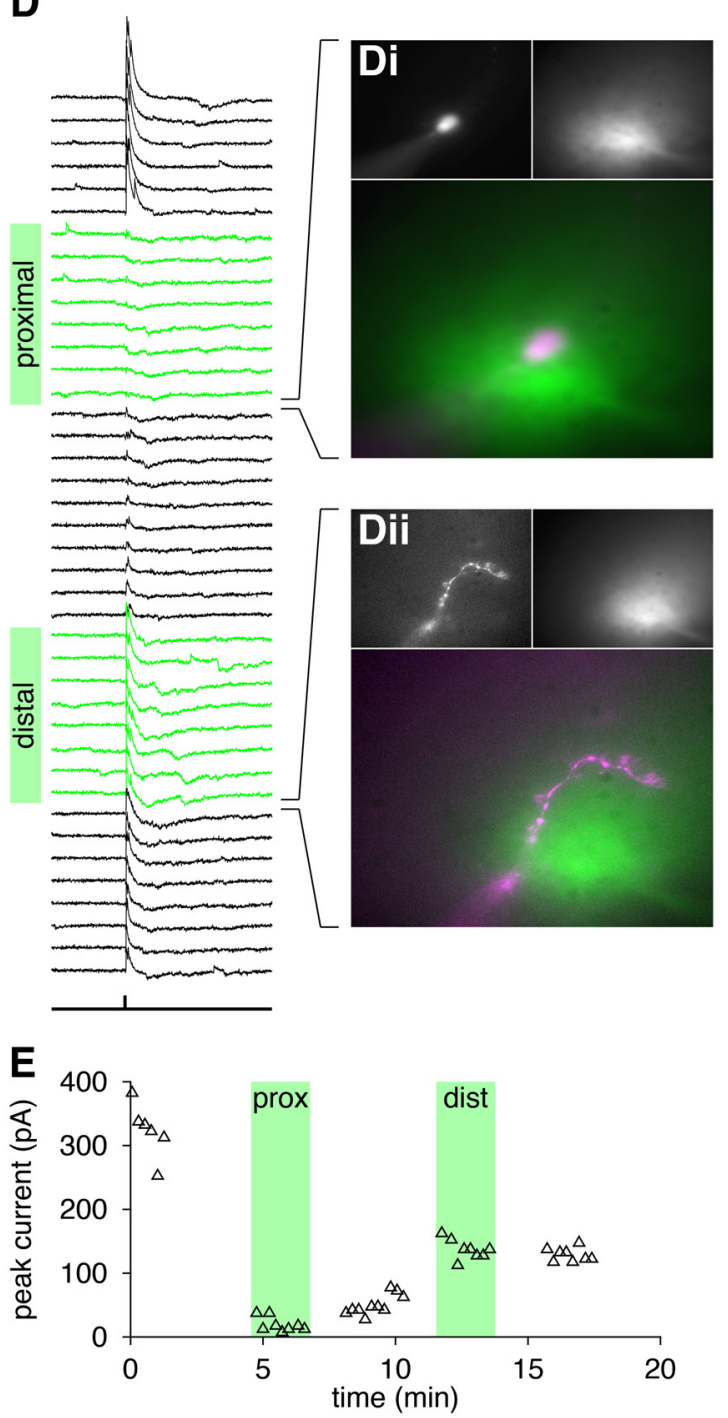

Figure 5. Feedforward inhibition onto GCs is localized to proximal somatodendritic and distal apical dendritic domains. A, Experimental design. Feedforward inhibitory currents were recorded in GCS (clamped at the reversal potential of synaptic excitation) while focally puffing the GABA $A_{A} R$ antagonist GBZ (with Alexa Fluor 488) near distal apical dendritic or proximal somatodendritic domains. $B$, Inhibitory current traces across multiple trials (top) after a single $0 \mathrm{SN}$ stimulation pulse (bottom) in a representative $\mathrm{GC}$, with transient application of $\mathrm{GBZ}$ near the soma (Bi; scale bar, $20 \mu \mathrm{m}$ ) or an apical dendritic branch (Bii). Note that GBZ (imaged just before puff termination) remained strongly localized throughout the duration of the puff application. C, Time course of peak inhibitory currents before, during (shaded regions), and after GBZ application. Gaps in data correspond to periods during which the puffing pipette was positioned and data were not collected. Note that both proximal (prox) somatodendritic and distal (dist) apical dendritic GBZ application reduced strongly the peak inhibitory currents recorded. $\boldsymbol{D}, \boldsymbol{E}$, Same as $\boldsymbol{B}$ and $\boldsymbol{C}$ for a second representative $\mathrm{GC}$ showing a strong reduction in peak inhibitory currents during proximal somatodendritic but not distal apical dendritic GBZ application. $\boldsymbol{F}$, The decrease in mean peak inhibitory current during proximal or distal GBZ application relative to the mean peak current preceding GBZ application. Red lines and points correspond to the representative cells shown in $\boldsymbol{B}$-E. Both proximal $\left(p=1.1 \times 10^{-3}\right.$, one-tailed $t$ test; $\left.n=5\right)$ and distal $(p=0.027$, one-tailed $t$ test; $n=7)$ GBZ application yielded average reductions in peak inhibitory currents that were significantly greater than zero. $G$, Same as $\boldsymbol{F}$ but plotting the decrease in peak inhibitory current for the trial immediately following the onset of GBZ application, at which point GBZ diffusion away from the site of application was at a minimum. Proximal GBZ application led to an immediate reduction in the peak inhibitory current ( $p=4.5 \times 10^{-3}$, one-tailed $t$ test; $\left.n=5\right)$, whereas distal GBZ application did not lead consistently to an immediate reduction in the peak inhibitory current ( $p=0.11$, one-tailed $t$ test, $n=7)$. IPL, Internal plexiform layer. ${ }^{*} p<0.05 ;{ }^{* *} p<0.01$. 
Therefore, we next characterized the subcellular localization of feedforward synaptic inhibition onto GCs using a pharmacological approach equivalent to several previous studies examining the subcellular features of synaptic excitation onto GCs (Halabisky and Strowbridge, 2003; Schoppa, 2006a). Specifically, we stimulated OSNs as above while focally puffing the $\mathrm{GABA}_{\mathrm{A}} \mathrm{R}$ antagonist GBZ near distal apical dendritic or proximal somatodendritic domains of GCs (Fig. 5A; see Materials and Methods). Focal application of GBZ near proximal somatodendritic domains robustly, reversibly, and rapidly decreased feedforward inhibition onto GCs (Fig. 5B-E), with five of five tested GCs exhibiting $>30 \%$ reduction in the peak inhibitory current within the first trial after the onset of GBZ application (Fig. 5G) and $>40 \%$ on average across multiple trials (Fig. $5 F$ ). In turn, focal application of GBZ near distal apical dendritic domains exhibited more heterogeneous effects, with some GCs exhibiting a clear and immediate decrease in feedforward inhibition (Fig. $5 B, C$ ) and other GCs exhibiting little to no decrease (Fig. $5 D, E$ ). Across seven tested GCs, three exhibited $>30 \%$ reduction in the peak inhibitory current on average (with two GCs exhibiting $>20 \%$ reduction in the first trial after the onset of GBZ application), whereas four exhibited minimal reductions (Fig. $5 F, G$ ). Given the limitations of our experimental design, in which GBZ was applied focally near a single dendritic branch, and that each GC extends numerous secondary apical dendritic branches that can be separated by $>100 \mu \mathrm{m}$ (Figs. 1-3), our results suggest that GCs receive feedforward inhibition on both proximal somatodendritic domains and throughout some or all of their distal apical dendritic branches, consistent with the ultrastructural localization of dSAC synapses onto GCs (Eyre et al., 2008). In total, our analyses of dSAC recruitment (Fig. 4) and the subcellular localization of inhibition onto GCs (Fig. 5) demonstrate collectively that dSAC-mediated feedforward inhibition onto GCs is well positioned to influence both GC firing and dendritic integration and GABA release (see below).

\section{Excitation and feedforward inhibition onto GCs scale in strength across different levels of sensory input}

Thus far, we have examined the synaptic input onto GCs after physiological activation of a single glomerulus. However, we have shown previously that multiple neighboring glomerular microcircuits can activate individual GCs (Kapoor and Urban, 2006; Arevian et al., 2008). This result and the relatively broad odor tuning of GCs (Tan et al., 2010) suggest collectively that GCs receive excitatory synaptic input from multiple glomerular microcircuits. Consequently, the strength of synaptic excitation onto GCs should scale with the strength of sensory input to the $\mathrm{MOB}$, with stronger sensory inputs (e.g., higher odor concentrations) activating more glomeruli than weaker sensory inputs (e.g., lower odor concentrations; Rubin and Katz, 1999; Meister and Bonhoeffer, 2001; Wachowiak and Cohen, 2001; Spors and Grinvald, 2002; Bozza et al., 2004; Spors et al., 2006; Fletcher et al., 2009). Whether feedforward synaptic inhibition onto GCs can likewise scale with sensory input strength will have critical consequences on GC recruitment by weak versus strong sensory inputs. Thus, we next sought to determine the relative scaling of excitation versus inhibition onto GCs downstream of weak (i.e., uniglomerular) versus strong (i.e., multiglomerular) sensory input to the MOB.

To achieve controllable activation of one or many glomeruli, we turned to an optogenetic strategy for stimulating OSNs. Acute slices were prepared from gene-targeted OMP-ChR2:EYFP mice that selectively express ChR2:EYFP in mature OSNs (Smear et al.,
2011). To confirm that a single glomerulus could be optogenetically activated comparable with our previous experiments using extracellular OSN stimulation, we performed control recordings from TCs as we photostimulated on- or off-beam glomeruli (Fig. $6 A$; see Materials and Methods). Indeed, photostimulation of on-beam glomeruli evoked highly reproducible LLD events (Fig. $6 C, E, F$ ) and firing (Fig. $6 D, G$ ) that was directly comparable with results obtained using extracellular OSN stimulation within individual glomeruli (Burton and Urban, 2014). In contrast, photostimulation of neighboring off-beam glomeruli evoked no excitatory currents (Fig. 6C,E, F) or firing (Fig. 6D, G) in TCs.

Having thus confirmed that we can optogenetically activate individual glomeruli, we next examined the synaptic input to GCs after uniglomerular versus multiglomerular photostimulation (Fig. 7A; see Materials and Methods). As above (Fig. 2), activation of a single glomerulus evoked an asynchronous barrage of excitatory events, as well as rapid and reliable synaptic inhibition (Fig. 7Ciii). Strikingly, expanding our photostimulation to multiple glomeruli increased dramatically the strength of synaptic excitation onto GCs (Fig. 7Ciii). Across all GCs, the peak excitatory current after multiglomerular versus uniglomerular photostimulation increased $1.8 \pm 0.9$-fold, from $-87.8 \pm 45.2$ to $-144.5 \pm 88.3 \mathrm{pA}$ (Fig. $7 D$ ). As a caveat, this increase in excitation strength onto GCs may arise partially from stronger illumination and activation of a single glomerulus at the center of our photostimulation. In particular, we suspect that TCs, which are more strongly driven by direct OSN input than MCs (Gire et al., 2012; Burton and Urban, 2014), may fire more in response to multiglomerular versus uniglomerular photostimulation. However, we note that displacing the multiglomerular photostimulation from centering on the originally photostimulated glomerulus to a neighboring glomerulus did not alter the excitation evoked onto GCs (data not shown). Moreover, in a subset of recordings $(n=4)$, we additionally confirmed that GCs received excitation from multiple neighboring glomerular microcircuits by sequentially photostimulating individual glomeruli (Fig. 7C). In total, our results (1) verify and extend our previous findings (Kapoor and Urban, 2006; Arevian et al., 2008) by directly showing that GCs receive convergent synaptic excitation from multiple glomerular microcircuits and (2) confirm that the strength of synaptic excitation onto GCs scales with the strength of sensory input to the MOB.

Of great interest, GCs also received feedforward inhibition from multiple neighboring glomerular microcircuits (Fig. 7C), and multiglomerular photostimulation dramatically increased the peak inhibitory current onto GCs by $2.6 \pm 1.8$-fold, from $78.5 \pm 72.8$ to $156.2 \pm 96.7$ pA (Fig. 7D). Moreover, on a cell-bycell basis, feedforward inhibition scaled in strength with excitation (Fig. 7E). Strikingly, this increase in the strength of synaptic input to GCs occurred with no apparent change in kinetics, with both uniglomerular and multi-glomerular photostimulation evoking highly asynchronous excitation and synchronous inhibition (Fig. $7 F, G$ ). Collectively, our results strongly suggest that asynchronous synaptic excitation and synchronous feedforward inhibition are critical regulators of GC recruitment by both weak and strong sensory input to the MOB.

Interestingly, the scaling of feedforward inhibition with excitation also suggests that GCs may exhibit primarily odor concentration-invariant firing in vivo, consistent with multiple previous examples (Wellis and Scott, 1990, their Fig. 5; Luo and Katz, 2001, their Fig. 8; Cang and Isaacson, 2003, their Fig. 10). Therefore, to begin to investigate the dependence of GC recruitment on the strength of sensory input to the MOB, we addition- 
A on-beam stimulation

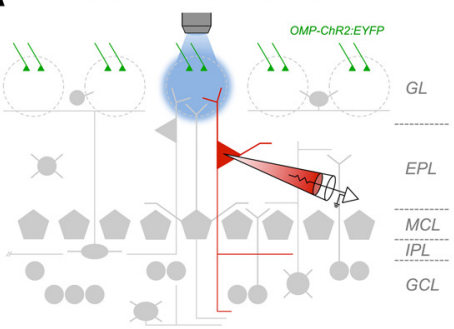

off-beam stimulation

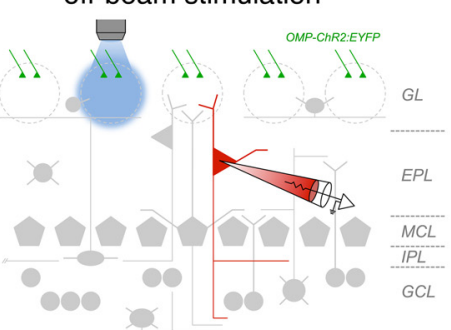

B
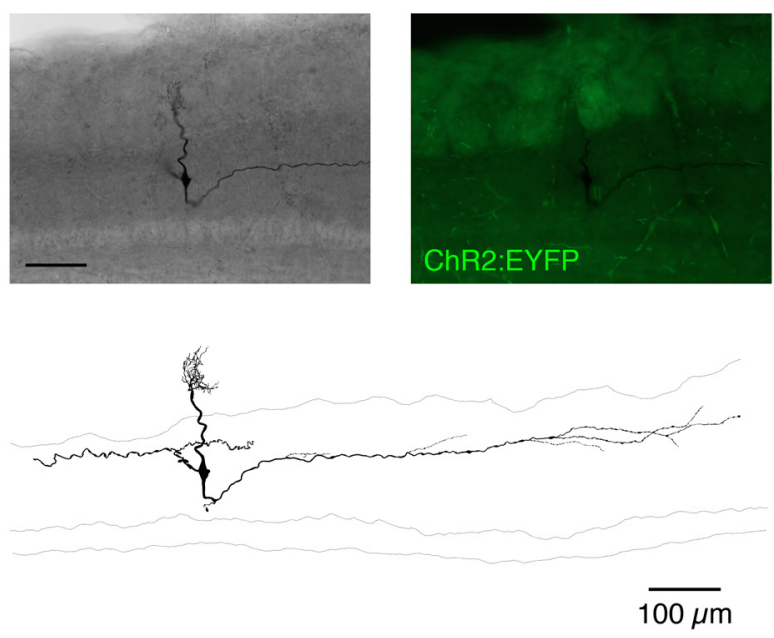

C

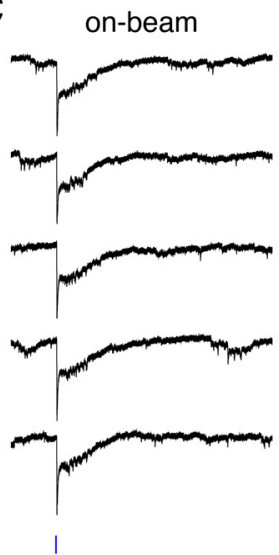

E

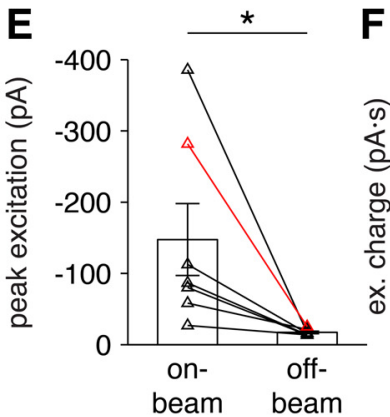

off-beam

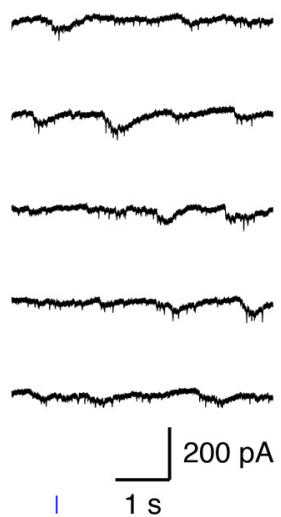

F

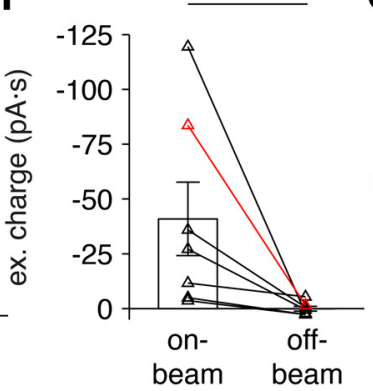

D

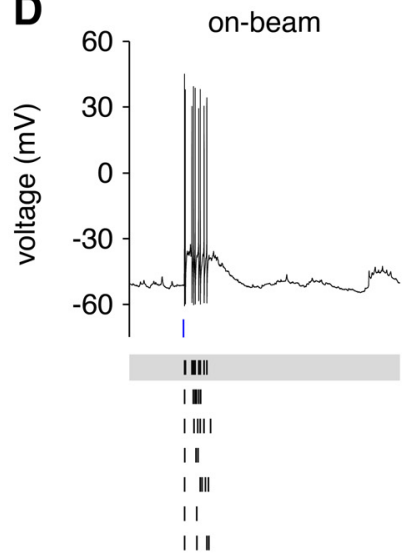

G

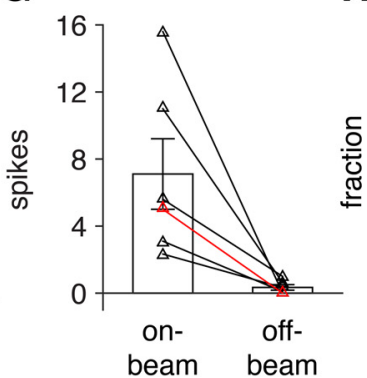

off-beam

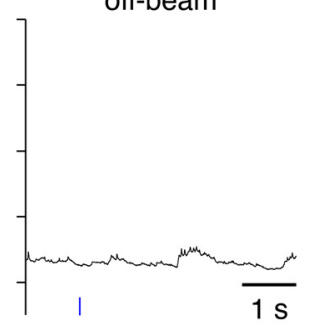

H

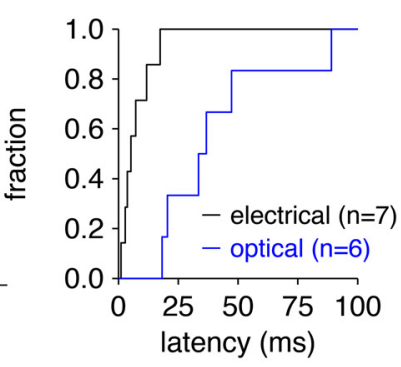

Figure 6. Optical activation of single glomeruli in gene-targeted OMP-ChR2:EYFP mouse brain slices. $\boldsymbol{A}$, Experimental design. $\boldsymbol{B}$, Bright-field (top left; 5 cale bar, $100 \mu \mathrm{m}$ ) and epifluorescent (top right) images and morphological reconstruction (bottom) of a representative TC. C, Example current traces after brief targeted photostimulation (blue line) of the on-beam glomerulus (left) or rostrally neighboring off-beam glomerulus (right) for the TC shown in B. D, Representative voltage traces (top) and raster plot of spike times across multiple trials (bottom) after brief targeted photostimulation (blue line) of the on-beam (left) or rostrally neighboring off-beam (right) glomerulus for the TC shown in $\boldsymbol{B}$. $\boldsymbol{E}-\mathbf{G}$, On-beam glomerular photostimulation evoked significantly greater peak excitatory currents $(\boldsymbol{E} ; p=0.020$, one-tailed paired $t$ test; $n=7)$, excitatory charge transfer $(\boldsymbol{F} ; p=0.025$, one-tailed paired $t$ test; $n=7)$, and spike rates $(\boldsymbol{G} ; p=0.012$, one-tailed paired $t$ test; $n=6$ ) in TCs than off-beam glomerular photostimulation. Red lines and points correspond to the representative cell shown in $\boldsymbol{B}-\boldsymbol{D}$. $\boldsymbol{H}$, Cumulative distributions of TC first-spike latencies after optical or extracellular stimulation of OSN axons within single glomerular microcircuits. Extracellular stimulation data from Burton and Urban (2014). IPL, Internal plexiform layer. ${ }^{*} p<0.05$.

ally examined the spiking response of GCs to uniglomerular versus multiglomerular photostimulation. Across six GCs exhibiting suprathreshold responses to glomerular photostimulation, uniglomerular photostimulation evoked $0.8 \pm 0.7$ spikes per trial (Fig. $7 \mathrm{H}, \mathrm{I}$ ), with varying first-spike latencies (Fig. $7 J$ ) and spike probabilities (data not shown), consistent with the response of GCs to extracellular OSN stimulation within a single glomerulus (Fig. 1). In the same GCs, expanding our photostimulation to multiple glomeruli evoked $2.4 \pm 2.1$ spikes per trial (Fig. 7 H,I). Although significant, this increase in firing is quite modest given the $\sim 55 \mathrm{pA}$ average increase in peak excitation (Fig. $7 D$ ), which alone would generate up to an $\sim 47 \mathrm{~Hz}$ increase in firing rate if injected at the soma (Table 3). Our results thus provide initial support for the hypothesis that feedforward inhibition scales with excitation to normalize GC firing across different levels of sensory input. Critically, such normalization will act to maintain GC 
A uni-glomerular stimulation

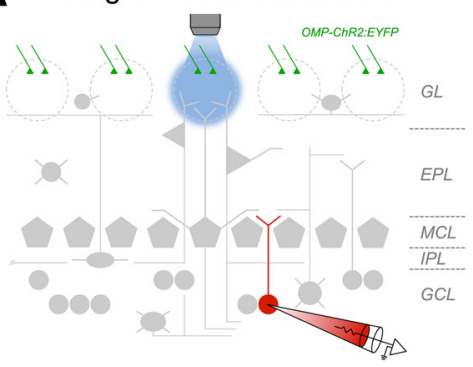

multi-glomerular stimulation

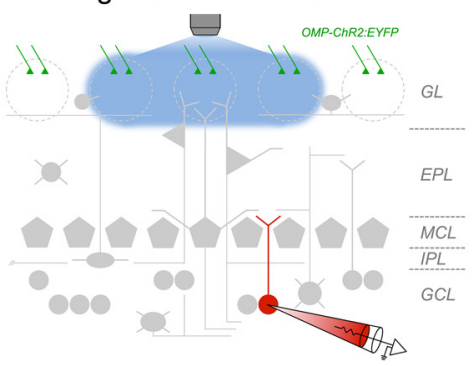

B
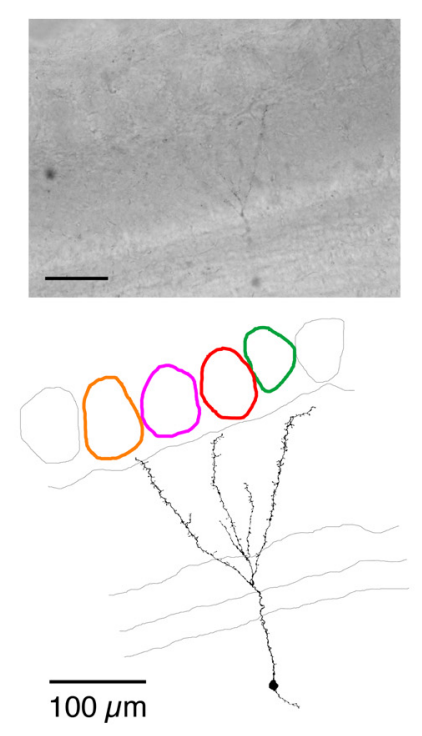

Cii
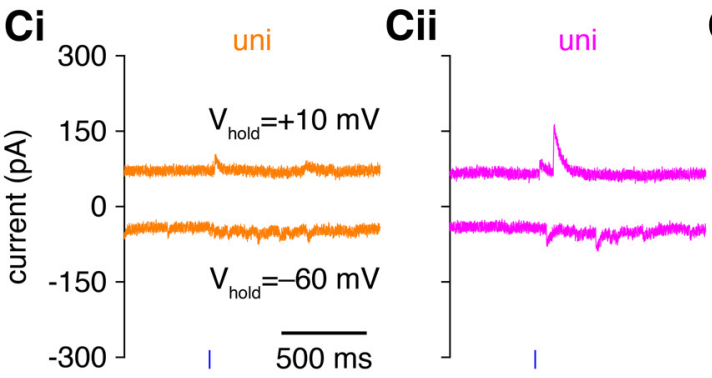

Ciii

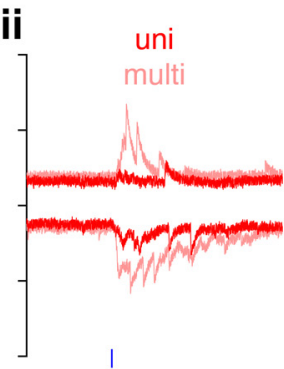

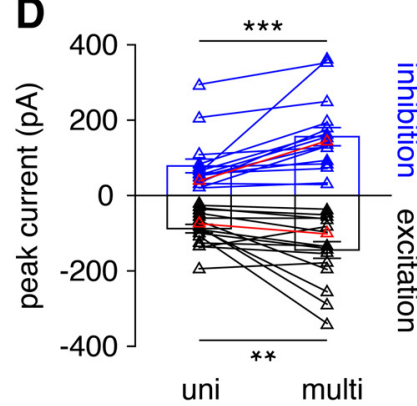

E

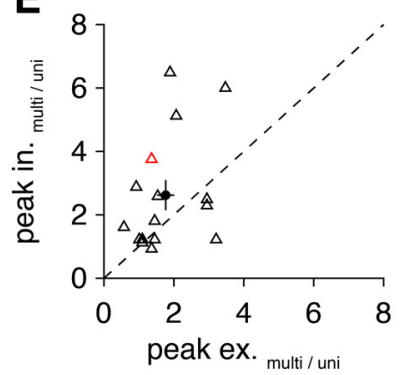

F

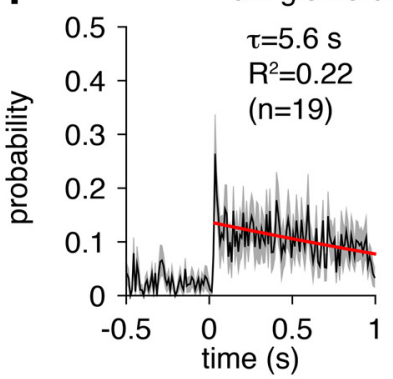

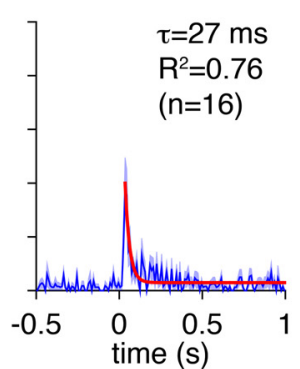

time (s)
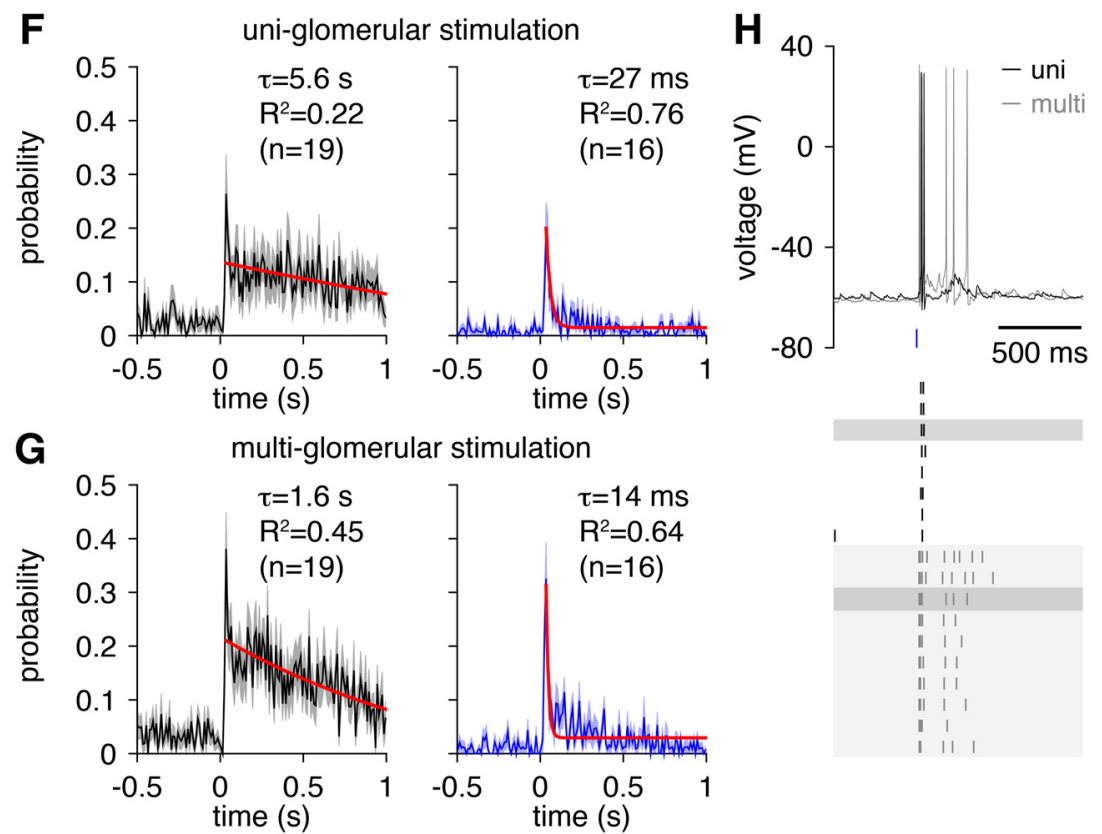
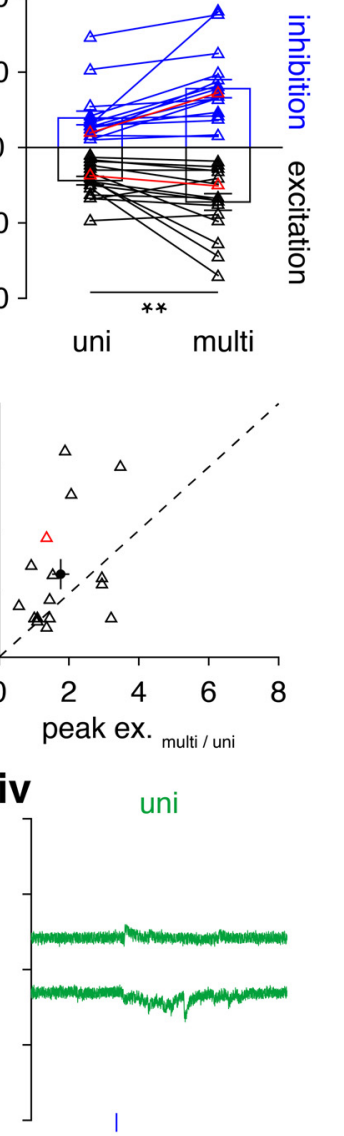
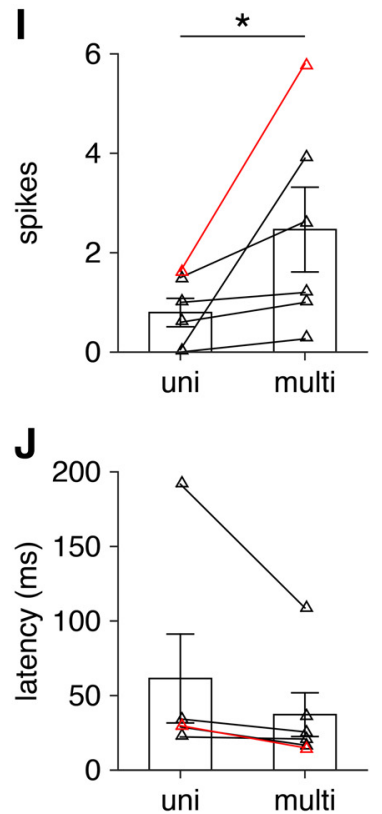

Figure 7. GCs receive convergent excitation and feedforward inhibition from multiple glomerular microcircuits. $\boldsymbol{A}$, Experimental design. $\boldsymbol{B}$, Bright-field image (top; scale bar, $100 \mu \mathrm{m}$ ) and morphological reconstruction (bottom) of a representative GC. C, Representative current traces after sequential uniglomerular (Ci-Civ) and multiglomerular (Ciii, light red) photostimulation (blue line) for the cell shown in $\boldsymbol{B}$. Colors of traces correspond to the glomerular boundaries reconstructed in $\boldsymbol{B}$. D. Peak excitatory and inhibitory synaptic currents measured within $500 \mathrm{~ms}$ of uniglomerular (uni) and multiglomerular (multi) photostimulation. Multiglomerular photostimulation significantly increased the peak excitatory $\left(p=7.3 \times 10^{-3}\right.$, one-tailed paired $t$ test) and inhibitory $(p=$ $4.2 \times 10^{-4}$, one-tailed paired $t$ test) currents measured across GCS $(n=16)$. Red lines and points correspond to the representative cell shown in $\boldsymbol{B}$ and $\boldsymbol{C}$. $\boldsymbol{E}$, The fold increase in peak inhibitory synaptic currents plotted against the fold increase in peak excitatory synaptic currents after multiglomerular versus uniglomerular photostimulation $(n=16)$. Black point shows mean \pm SEM; red point corresponds to the representative cell shown in $\boldsymbol{B}$ and $C$. A strong but statistically insignificant trend existed toward a greater increase in inhibition than excitation ( $p=0.058$, two-tailed paired $t$ test). No linear relationship existed between the fold increase in inhibition and excitation ( $p=0.12$, linear regression). $F, G$, Mean PSTHs of EPSC (left, black) and IPSC (right, blue) times after uniglomerular $(\boldsymbol{F})$ and multiglomerular $(\boldsymbol{G})$ photostimulation. Shading denotes mean \pm SEM. Red line shows a single-exponential fit. $\boldsymbol{H}$, Representative voltage traces (Figure legend continues.) 
activity in a range that is sensitive to the cooperative activation of MCs/TCs (Arevian et al., 2008; Urban and Arevian, 2009), supporting decorrelation of MCs/TCs via activity-dependent lateral inhibition over a large odor concentration range. Moreover, our results importantly motivate a more systematic investigation of the odor concentration dependence of GC activity in vivo.

\section{Feedforward inhibition regulates GC spike timing}

To further understand how asynchronous excitation and synchronous feedforward inhibition regulate GC activity, we performed a series of simulations using a biophysical multicompartmental GC model (Fig. $8 A$ ) that recapitulates a wide array of physiological GC activity patterns (Li and Cleland, 2013). To simulate synaptic excitation onto the model GC after activation of a single glomerulus, we delivered 10-30 excitatory events per trial, based on previous estimates that each GC dendritic tree is decorated with 100-300 large spines or "gemmules" (Woolf et al., 1991b) and that $\sim 10 \%$ of gemmules receive excitatory input from a single glomerular microcircuit (Egger et al., 2005). Each excitatory event (mediated by both AMPAR and NMDAR conductances; see Materials and Methods) was delivered to the gemmule body compartment (Fig. 8A), corresponding to the site of reciprocal dendrodendritic synapses (Rall et al., 1966). To examine the influence of the temporal structure of excitation on GC firing, excitatory event times were either drawn randomly from a distribution matching the mean PSTH of EPSC times (Fig. $8 B$ ) or were made artificially synchronous. To examine the influence of feedforward inhibition on GC firing, single inhibitory synaptic events were delivered to the soma and distal apical dendritic compartments (Fig. 8A), matching previous ultrastructural localization of dSAC-GC synapses (Eyre et al., 2008) and our functional localization of feedforward inhibition onto GCs (Fig. 5). Inhibition followed the onset of the mean experimental excitation time course (or the onset of the artificially synchronous excitation) by $6.9 \mathrm{~ms}$ (Fig. 8B), matching the mean delay observed between excitation and inhibition (see above). Finally, to ensure the robustness of our simulation results, excitatory event strength (and therefore the excitation/inhibition ratio) was also systematically varied by $\pm 20 \%$ across simulations.

Artificially synchronous excitation reliably evoked $2.0 \pm 0.3$ spikes per trial (range, 1-3) over a narrow distribution of short first-spike latencies ( $7.83 \pm 0.08 \mathrm{~ms}$; Fig. $8 C$; data not shown). This activity pattern deviates substantially from the broader distributions of spike numbers and latencies observed in vivo in response to odors (Wellis and Scott, 1990; Luo and Katz, 2001; Cang and Isaacson, 2003; Margrie and Schaefer, 2003; Labarrera et al., 2013; Cazakoff et al., 2014; Fukunaga et al., 2014) and in vitro in response to physiological glomerular activation (Fig. 1) but matches previous accounts of $\mathrm{GC}$ activity in vitro in response to synchronous MC/TC activation (Egger et al., 2005). Inclusion of feedforward inhibition reduced the number of spikes per trial to $1.0 \pm 0.2$ (range, 1-2) but had no effect on the first-spike latency (Fig. 8C), as expected from the delayed onset of inhibition relative to excitation. In strong contrast to the GC activity patterns evoked by artificially synchronous excitation, physiol-

\section{$\leftarrow$}

(Figure legend continued.) (top) and raster plot of spike times across multiple trials (bottom) after uniglomerular (no shading) or multiglomerular (gray shading) photostimulation (blue line) for a representative $\mathrm{GC}$ (morphology not shown). I, J, Multiglomerular photostimulation evoked significantly more spikes per trial $(\boldsymbol{I} ; p=0.039$, one-tailed paired $t$ test $)$ and tended to yield shorter first-spike latencies $(\boldsymbol{J} ; p=0.091$, one-tailed paired $t$ test) than uniglomerular photostimulation $(n=6)$. IPL, Internal plexiform layer. ${ }^{*} p<0.05 ;{ }^{* *} p<0.01 ;{ }^{* * *} p<0.001$. ogically asynchronous excitation evoked a much broader distribution of $1.3 \pm 0.8$ spikes per trial (range, $0-6$ ) over a wide distribution of mean first-spike latencies $(125.9 \pm 43.9 \mathrm{~ms}$; Fig. $8 D-F$ ), paralleling our experimental observations (Fig. 1) and the odor-evoked GC activity observed in vivo (Wellis and Scott, 1990; Luo and Katz, 2001; Cang and Isaacson, 2003; Margrie and Schaefer, 2003; Labarrera et al., 2013; Cazakoff et al., 2014; Fukunaga et al., 2014).

Strikingly, inclusion of single inhibitory somatic and distal apical dendritic events substantially increased and broadened the distribution of first-spike latencies (194.5 $\pm 61.4 \mathrm{~ms}$; Fig. $8 D-F$ ). Moreover, this change in spike timing substantially reduced the trial-to-trial spike-time reliability (Fig. 8G,H). In agreement with our simulation results, we found that blocking feedforward inhibition onto GCs with bath application of GBZ $(10 \mu \mathrm{M})$ consistently reduced GC first-spike latencies from $145.4 \pm 95.8$ to $78.1 \pm 106.4 \mathrm{~ms}$ in response to extracellular OSN stimulation (Fig. 8I). Although bath application of GBZ did not consistently increase spike-time reliability as predicted $(0.23 \pm 0.34$ vs $0.23 \pm$ 0.20 , before vs after GBZ application), the GCs most strongly affected by GBZ (exhibiting reductions in first-spike latency $>80$ $\mathrm{ms}$ ) exhibited a consistent increase in spike-time reliability (Fig. $8 J)$. Thus, even with network-wide changes in activity triggered by bath application of GBZ, at least a subset of the experimentally recorded GCs directly matched our simulation results. In total, the results of our simulations, which are broadly consistent with our experimental recordings, reveal that feedforward inhibition strongly delays GC firing. Importantly, feedforward inhibition can thereby complement other mechanisms regulating spike timing in GCs. In particular, GCs express A-type potassium channels, which blunt rapid excitation to delay firing (Schoppa and Westbrook, 1999; Kapoor and Urban, 2006; Schoppa, 2006a) but inactivate during sustained excitatory input, such as from theta frequency glomerular activation (Schoppa, 2006a). Thus, feedforward inhibition, which is recruited reliably across theta frequency glomerular activation (Fig. 3), likely plays a dominant role in regulating the respiratory coupling of GC spike timing (Cazakoff et al., 2014) and subthreshold depolarization (Youngstrom and Strowbridge, 2015) during bouts of sustained odor sampling. Of great interest, our results further demonstrate that feedforward inhibition can reduce the overall temporal fidelity of firing when excitatory input is strongly asynchronous. Strikingly, this desynchronizing role directly contrasts with the ability of feedforward inhibition to enhance spiking precision when excitatory input is only weakly asynchronous (see Discussion). Furthermore, by broadening GC spike latencies, feedforward inhibition will enhance the decorrelation of principal neuron activity (Giridhar and Urban, 2012) and thus likely plays a critical role in complex olfactory-guided behavior (e.g., difficult odor discriminations).

\section{Feedforward inhibition regulates subcellular GC activity and $\mathrm{Ca}^{2+}$ dynamics}

Although our simulations have thus far demonstrated that feedforward inhibition influences GC spike timing (Fig. 8), previous data suggest that GC dendrites are also capable of releasing GABA independent of somatic action potentials (Isaacson and Strowbridge, 1998). Indeed, the low odor-evoked firing rates of GCs in vivo (Wellis and Scott, 1990; Luo and Katz, 2001; Cang and Isaacson, 2003; Margrie and Schaefer, 2003; Labarrera et al., 2013; Cazakoff et al., 2014; Fukunaga et al., 2014) together with the substantial evidence of isolated dendritic spikes in GCs in vivo (Mori and Takagi, 1978; Wellis and Scott, 1990; Luo and Katz, 
A

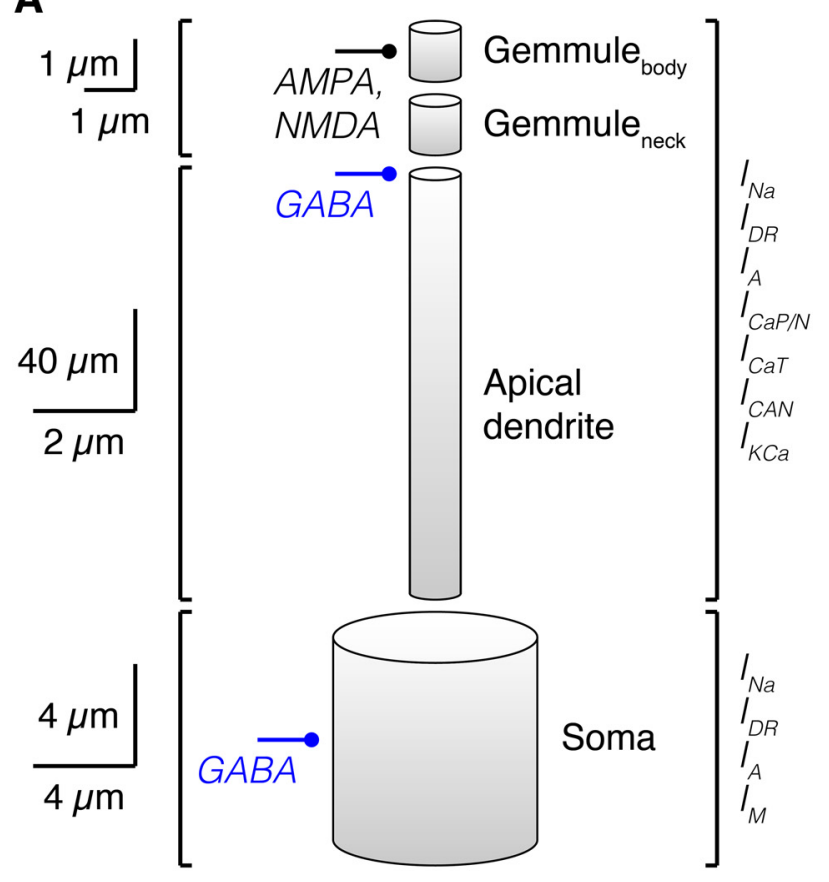

B

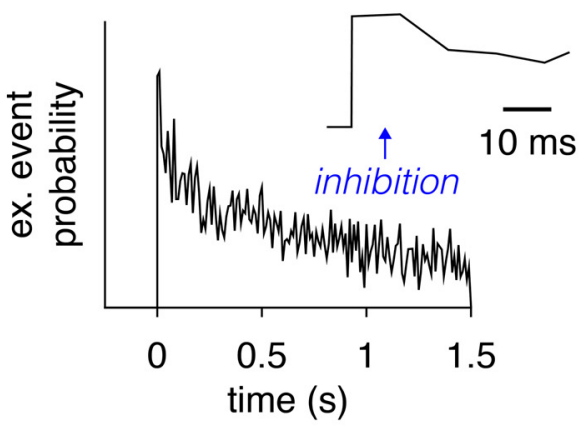

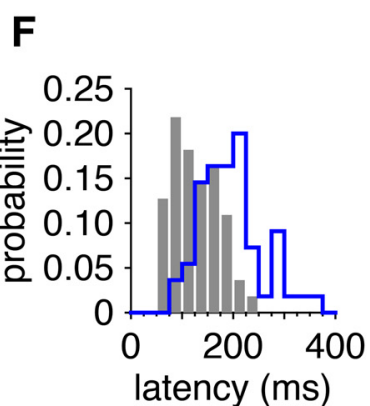

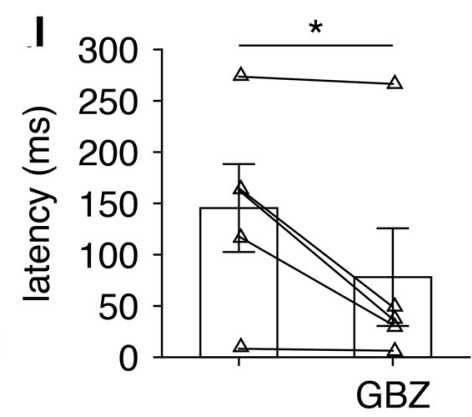

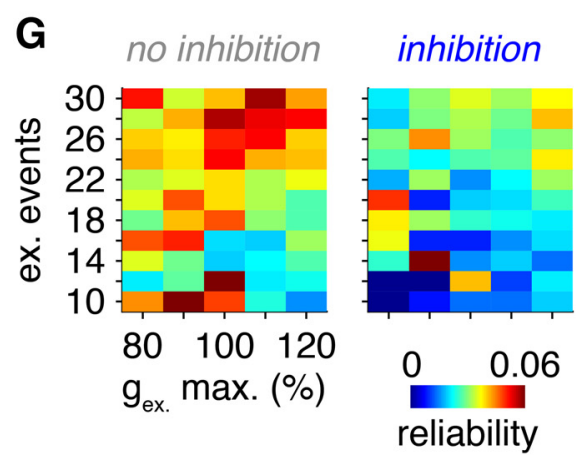
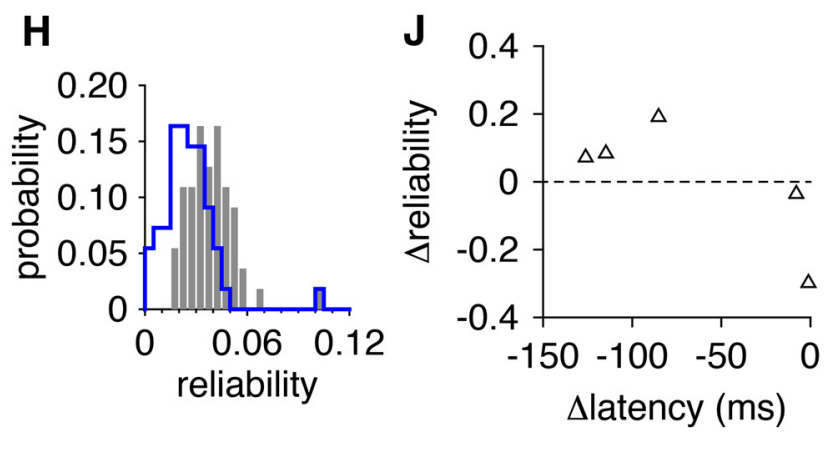

Figure 8. Feedforward inhibition and asynchronous excitation interact to reduce the temporal fidelity of GC firing. $A$, Biophysical multicompartmental GC model properties (see Materials and Methods; Li and (leland, 2013). B, Ten to 30 excitatory events were delivered either synchronously or asynchronously with probabilistic latency drawn from (Figure legend continues.) 
A

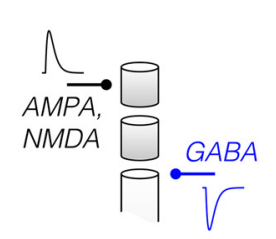

B

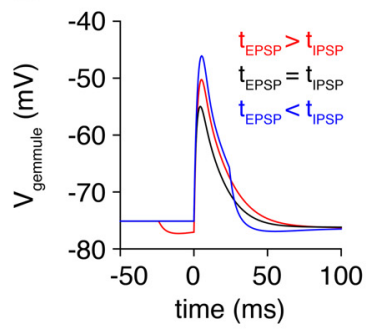

C

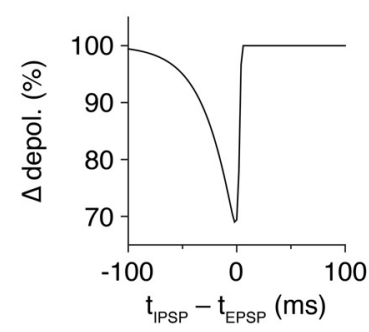

D

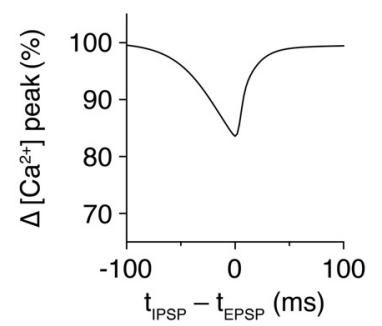

Figure 9. Feedforward inhibition attenuates gemmule depolarization and $\mathrm{Ca}^{2+}$ influx triggered by coincident synaptic excitation. $\boldsymbol{A}, \boldsymbol{B}$, Experimental design. The influence of a single apical dendritic IPSP on the local gemmule depolarization and $\mathrm{Ca}^{2+}$ influx evoked by a single EPSP was monitored while varying the relative EPSP-IPSP timing. C, $\boldsymbol{D}, \mathbf{A}$ single apical dendritic IPSP substantially reduced the maximum gemmule depolarization $(\boldsymbol{C})$ and $\mathrm{Ca}^{2+}$ influx $(\boldsymbol{D})$ evoked by a coincident or subsequent EPSP.

2001; Labarrera et al., 2013) and in vitro (Pinato and Midtgaard, 2005; Zelles et al., 2006; Fig. 1) and the recent demonstration of gemmule-localized voltage-gated sodium currents (Bywalez et al., 2015) suggest that a large proportion of GCmediated inhibition of MCs/TCs arises from highly localized dendritic branch- (or gemmule-) specific GABA release independent of somatic action potentials, comparable with the "parallel processing" performed by amacrine cells in the retina (Grimes et al., 2010). Thus, feedforward inhibition targeting distal apical dendritic domains of GCs is likely of greatest importance in regulating GC activity at the subcellular level. Therefore, we next examined what influence feedforward inhibition onto apical dendrites has on local gemmule activity evoked by individual excitatory inputs.

Specifically, we monitored the membrane potential and total intracellular $\mathrm{Ca}^{2+}$ concentration within the gemmule body compartment of our model GC while delivering single excitatory and inhibitory events with varying temporal lags (Fig. 9B), consistent with our observation that individual excitatory events both preceded and followed feedforward inhibition (Figs. 2, 3, 7). Critically, we observed that a single inhibitory event targeting the distal apical dendrite at the base of the gemmule (Fig. 9A) triggered a substantial reduction (up to $\sim 30 \%$ ) in the peak gemmule depolarization (Fig. 9C) and a more moderate reduction (up to $\sim 15 \%$ ) in the peak $\mathrm{Ca}^{2+}$ concentration change (Fig. 9D) evoked by a coincident excitatory event at the gemmule body (Fig. 9A). Of note, the drop in local $\mathrm{Ca}^{2+}$-dependent GC GABA release caused by coincident feedforward inhibition is expected to be even greater than the observed decrease in total $\mathrm{Ca}^{2+}$ concentra-

\footnotetext{
$\leftarrow$

(Figure legend continued.) the average PSTH of EPSC times after extracellular OSN stimulation. Inset, Zero to one inhibitory events were delivered to the distal apical dendritic and proximal somatodendritic domains with latency $6.9 \mathrm{~ms}$ after the onset of probabilistic (or artificially synchronous) excitation. $C$, Representative simulation with 20 artificially synchronous excitatory events $\left(g_{\text {ex }} \max =110 \%\right)$ and feedforward inhibition (blue trace) or no inhibition (black trace). $\boldsymbol{D}$, Representative simulation (top) and raster plot of spike times across multiple simulations (middle) with 20 physiologically asynchronous excitatory events $\left(g_{\mathrm{ex}} \mathrm{max}=110 \%\right)$ and feedforward inhibition (blue trace) or no inhibition (black trace) after simulated glomerular activation (bottom). $\boldsymbol{E}$, Mean first-spike latency (averaged across 50 trials) for varying numbers and strengths of asynchronous excitatory inputs with feedforward inhibition (right) or without (left). $\boldsymbol{F}$, Distribution of mean first-spike latencies for all permutations shown in $\boldsymbol{E}$. $\boldsymbol{G}, \boldsymbol{H}$, Same as $\boldsymbol{E}$ and $\boldsymbol{F}$ for suprathreshold trial-to-trial spike-time reliability. I, Bath application of GBZ significantly reduced $\mathrm{GC}$ first-spike latencies evoked by extracellular OSN stimulation $(p=0.039$, one-tailed paired $t$ test; $n=5$ ), matching simulation predictions $(\boldsymbol{E}, \boldsymbol{F})$. J, Change in mean suprathreshold trial-to-trial spike-time reliability versus change in mean first-spike latencies after bath application of GBZ. GCs exhibiting strong reductions in first-spike latencies likewise exhibited increased spike-time reliabilities, approximately matching simulation predictions $(\mathbf{G}, \boldsymbol{H}) .{ }^{*} p<0.05$.
}

tion (Fig. 9D) given the strong coupling of GABA release to $\mathrm{Ca}^{2+}$ influx specifically through local NMDARs (Chen et al., 2000; Halabisky et al., 2000) and the localization of metabotropic $\mathrm{GABA}_{\mathrm{B}} \mathrm{Rs}$ to presynaptic GC compartments (Isaacson and Vitten, 2003). These results thus confirm that even a single inhibitory event can markedly attenuate local dendritic depolarization, $\mathrm{Ca}^{2+}$ influx, and consequent GABA release to disinhibit select principal neurons (see Discussion).

\section{Discussion}

\section{Overview}

GC-mediated inhibition is critical to patterning sensory-evoked $\mathrm{MC} / \mathrm{TC}$ activity, yet how sensory input recruits GC activity remains incompletely understood. Therefore, we have examined systematically how GCs integrate synaptic excitation and inhibition downstream of sensory input to the MOB. We show for the first time that OSN activation not only triggers highly asynchronous excitation onto GCs but also short-latency, synchronous GABAergic inhibition via a canonical disynaptic MC/TC- dSAC feedforward circuit (Fig. 10A). Moreover, each GC receives both excitation and feedforward inhibition from multiple glomerular microcircuits. Thus, as the strength of sensory input to the MOB increases and more glomeruli are activated, both excitation and feedforward inhibition onto GCs increase, maintaining a balanced synaptic drive and normalizing GC firing. We further reveal that feedforward inhibition interacts with highly asynchronous excitation to desynchronize GC firing, in marked contrast to the role of feedforward inhibition in synchronizing firing in other brain regions. Additionally, feedforward inhibition attenuates depolarization in local dendritic compartments to promote independent processing between dendritic compartments. Collectively, our results identify feedforward inhibition onto GCs as a core feature of MOB circuitry and establish asynchronous excitation and feedforward inhibition as critical regulators of GC activity.

Indirect evidence of feedforward inhibition onto GCs has been observed previously in the salamander olfactory bulb (Wellis and Kauer, 1994), which, together with our current findings, suggests strongly that feedforward inhibition onto GCs is a robust and conserved feature of olfactory circuits. However, of note, two previous studies failed to observe robust feedforward inhibition onto GCs. First, Schoppa (2006a) observed bicuculline-sensitive events in only 2 of 12 GCs tested. These recordings were obtained under high intracellular $\mathrm{Cl}^{-}$concentrations, however, making it likely that the coincident EPSCs evoked by glomerular activation occluded any IPSCs, which would also be downward-going events under these conditions. We further note that this previous study evoked synaptic input onto GCs using trains of ONL stimulation pulses collectively 

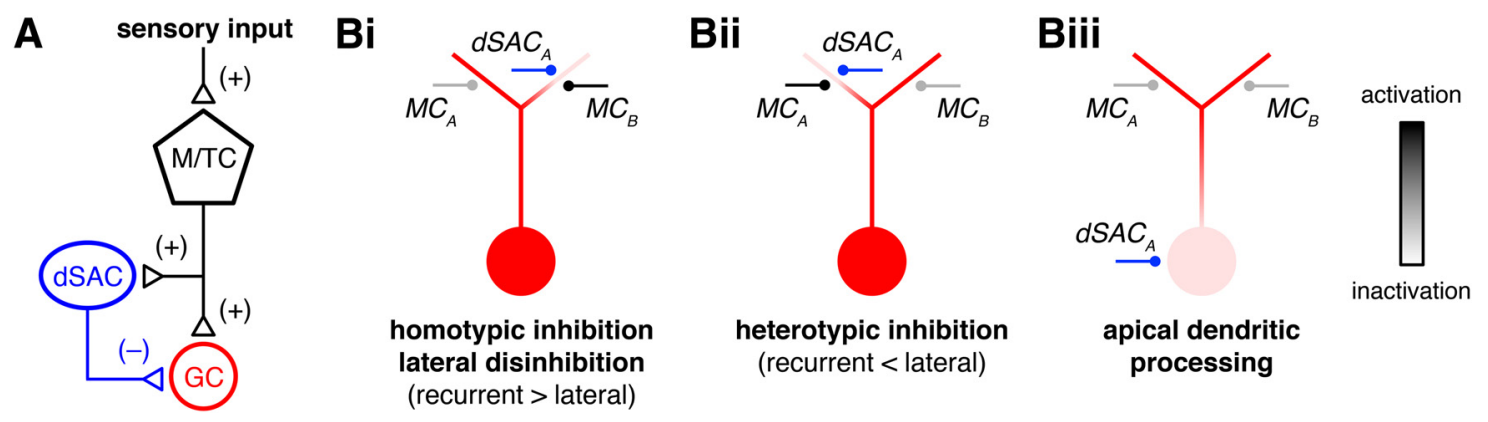

Figure 10. Feedforward inhibition onto GCs is a core feature of MOB circuitry that regulates GC-mediated inhibition of principal neurons. $A$, Canonical circuit diagram of GC synaptic inputs. Sensory input to the MOB activates MCS/TCs, which monosynaptically and asynchronously excite GCs and disynaptically and synchronously inhibit GCs via dSAC-mediated feedforward inhibition. $B$, The subcellular organization of excitation and feedforward inhibition can regulate local GC depolarization and consequent GABA release to control the balance between dendrodendritic recurrent and

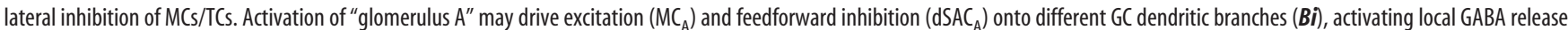
while inactivating remote $G A B A$ release, yielding stronger recurrent inhibition of $M C_{A}$ than lateral inhibition of $M C_{B}$ and potentially disinhibiting $M C_{B}$. Conversely, activation of glomerulus $A$ may drive excitation and feedforward inhibition onto the same $\mathrm{GC}$ dendritic branch (Bii), inactivating local GABA release while activating remote GABA release to preferentially drive lateral inhibition. Feedforward inhibition onto any $\mathrm{GC}$ dendritic branch (Bi, Bii), and particularly onto proximal somatodendritic domains (Biii), can attenuate propagation of dendritic depolarization to the soma, supporting local dendritic spikes and independent, parallel processing between different $\mathrm{GC}$ dendritic branches.

lasting $\sim 30 \mathrm{~ms}$. Thus, the short-latency feedforward inhibition that we observed, which predominantly occurred within $30 \mathrm{~ms}$ of OSN stimulation, was also likely occluded by the patterned ONL stimulation. Second, Labarrera et al. (2013) observed odor-evoked IPSCs in only 20\% of GC-odor pairs in the anesthetized mouse (compared with the $\sim 70 \%$ of pairs exhibiting odor-evoked excitation). However, it is likely that some odor-evoked IPSCs were missed as a result of coincident excitation and incomplete voltage clamp of distal dendritic branches, similar to our own observations in the acute slice preparation (see Materials and Methods). Furthermore, a large fraction of the odor-evoked excitation observed in their study likely originated from centrifugal inputs to GCs (Balu et al., 2007; Boyd et al., 2012; Markopoulos et al., 2012), which may not be directly coupled to the feedforward inhibitory circuits characterized in our study. Thus, we expect that, although GCs typically do not exhibit net inhibitory responses to odors in vivo, feedforward inhibition nevertheless plays a widespread and critical role in regulating GC spike timing and subcellular activity in vivo.

\section{Feedforward inhibition regulates the balance between recurrent and lateral inhibition of principal neurons} Understanding how feedforward inhibition onto GCs influences sensory processing in the MOB will ultimately require precise knowledge of the subcellular organization of excitation and feedforward inhibition onto each GC. For example, activity of one MC/TC may evoke excitation and feedforward inhibition onto distinct GC dendritic branches, resulting in strong recurrent inhibition but attenuated lateral inhibition (i.e., net "homotypic inhibition"; Fig. 10Bi). Of note, such organization likewise provides a potential mechanism for lateral disinhibition between MCs/TCs. Alternatively, activity of one MC/TC may evoke excitation and feedforward inhibition onto the same dendritic branch, leading to attenuated recurrent inhibition but strong lateral inhibition (i.e., net "heterotypic inhibition"; Fig. 10Bii). In addition to shifting the balance between recurrent and lateral inhibition, feedforward inhibition onto GC dendrites and proximal somatodendritic domains (Fig. 10Biii) will limit the propagation of dendritic depolarization to the soma, fostering dendritic branch-specific spiking and compounding the parallel processing capacity of each GC. Moreover, the termination of $\sim 10 \%$ of dSAC synapses in the EPL directly onto GC gemmules (Eyre et al., 2008) may further enhance the compartmentalization of feedforward inhibition (Chiu et al., 2013; Higley, 2014) to promote subcellular modulation of GABA release from individual GC gemmules.

\section{Feedforward inhibition enables dynamic modulation of olfactory bulb network rhythms}

GC-mediated inhibition of principal neurons strongly drives gamma frequency network rhythms in the MOB (Friedman and Strowbridge, 2003; Neville and Haberly, 2003; Lagier et al., 2004; Bathellier et al., 2006; Schoppa, 2006b; Lepousez and Lledo, 2013; Fukunaga et al., 2014). We hypothesize that feedforward inhibition onto GCs in turn suppresses MOB network rhythms in at least two ways. First, feedforward inhibition reduces GABA release from GCs and will thereby decouple MC/TC and GC activity. Second, feedforward inhibition interacts with asynchronous synaptic excitation to reduce the temporal fidelity of GC firing. This finding is in marked contrast to canonical models in which feedforward inhibition enhances spike-time precision (Pinto et al., 1996; Pouille and Scanziani, 2001) and depends on the strongly asynchronous time course of synaptic excitation onto GCs. Specifically, rapid feedforward inhibition suppresses GC firing during the initial, relatively synchronous phase of excitation, allowing the later, more asynchronous phase of excitation to instead drive firing, yielding lower spike-time precision. By thus reducing the temporal fidelity of GC firing, feedforward inhibition will desynchronize odor-evoked firing across GCs and thereby disrupt the synchronization of MCs/TCs by coincident inhibition (Galán et al., 2006; Schoppa, 2006b). Blocking feedforward inhibition onto GCs (e.g., through dSAC-specific neuromodulation) should thus strengthen MC/TC-GC interactions and enhance GC synchronization, promoting the synergistic synchronization of MCs/TCs linked by lateral inhibition (Marella and Ermentrout, 2010). Indeed, consistent with our hypothesis, deletion of the main $\mathrm{GABA}_{\mathrm{A}} \mathrm{R} \beta$ subunit expressed in GCs significantly enhances $\mathrm{MOB}$ oscillatory power during olfactory-guided behavior (Nusser et al., 2001). Thus, regulating dSAC activity represents a novel mechanism for dynamically modulating $\mathrm{MOB}$ network rhythms.

\section{Inclusion of dSACs in future models of olfaction}

Here, we show that dSACs respond to OSN stimulation with rapid and reliable firing that is coincident with feedforward inhibition onto GCs. Although our results thus argue strongly that dSACs mediate feedforward inhibition onto GCs, it remains pos- 
sible that other neuron types also contribute to this inhibition. In particular, transynaptic viral tracing studies have identified both dSACs and EPL interneurons (EPL-INs) as presynaptic to GCs (Arenkiel et al., 2011; Deshpande et al., 2013; Miyamichi et al., 2013; Garcia et al., 2014). Note, however, that ultrastructural (Toida et al., 1996; Lepousez et al., 2010) and functional (Huang et al., 2013; Kato et al., 2013) analyses have observed no direct synapses between EPLINs and GCs, suggesting that GCs infect EPL-INs via tripartite-like connections with MCs/TCs (Garcia et al., 2014). Other EPL-INs that are somatostatin-, parvalbumin-, vasointestinal peptide-, and corticotropin-releasing hormone-negative may mediate feedforward inhibition onto GCs, but these will represent a small fraction of MOB neurons compared with dSACs (Eyre et al., 2009).

Current models of olfaction generally do not include dSACs. However, the prevalence, connectivity patterns, and functional roles of dSACs argue compellingly for their integration into future models. Specifically, dSACs comprise a large population of MOB interneurons (Price and Powell, 1970b), numbering $\sim 13,500$ per rodent $\mathrm{MOB}$ or three to four principal neurons per dSAC (Eyre et al., 2009), comparable with the principal neuron/ interneuron ratio in the neocortex (Markram et al., 2004). Additionally, dSACs form extensive axonal arbors, conferring a high degree of connectivity onto other MOB interneurons (Eyre et al., 2009; Miyamichi et al., 2013), including adult-born neurons (Arenkiel et al., 2011; Deshpande et al., 2013). The unique properties of dSAC inputs are also likely of critical importance. Notably, dSACs receive the strongest centrifugal excitation from the piriform cortex of all MOB cell types (Boyd et al., 2012). Moreover, our current results suggest that dSACs may be recruited preferentially by TCs, thus identifying an additional circuit feature by which MCs and TCs mediate parallel processing of olfactory information (Fukunaga et al., 2012; Igarashi et al., 2012; Adam et al., 2014; Burton and Urban, 2014; Otazu et al., 2015).

Of utmost importance, several findings have now demonstrated that dSACs govern multiple aspects of MOB activity. Foremost, we have shown that dSAC-mediated feedforward inhibition normalizes GC spike numbers and regulates GC spike timing and subcellular activity and can thereby control the decorelation and temporal patterning of $\mathrm{MC} / \mathrm{TC}$ activity across different levels of sensory input. Through centrifugal excitation, dSACs can likewise regulate GC activity via feedback inhibition (Boyd et al., 2012; Oswald and Urban, 2012), providing a substrate for top-down modulation of olfactory processing (Restrepo et al., 2009). Additionally, GABAergic input from dSACs is essential for the integration and maturation of adult-born GCs (Pallotto et al., 2012), which can significantly influence olfaction (for review, see Lepousez et al., 2013). Subsets of dSACs likely regulate olfaction in numerous other ways as well, including via state-dependent and persistent firing (Pressler and Strowbridge, 2006, Pressler et al., 2013) and through unique axonal projections, including GL-projecting dSACs (Eyre et al., 2008, 2009) and cortical-projecting dSACs (Kosaka and Kosaka, 2007, 2010; Eyre et al., 2008).

\section{References}

Abraham NM, Egger V, Shimshek DR, Renden R, Fukunaga I, Sprengel R, Seeburg PH, Klugmann M, Margrie TW, Schaefer AT, Kuner T (2010) Synaptic inhibition in the olfactory bulb accelerates odor discrimination in mice. Neuron 65:399-411. CrossRef Medline

Adam Y, Livneh Y, Miyamichi K, Groysman M, Luo L, Mizrahi A (2014) Functional transformations of odor inputs in the mouse olfactory bulb. Front Neural Circuits 8:129. CrossRef Medline

Arenkiel BR, Hasegawa H, Yi JJ, Larsen RS, Wallace ML, Philpot BD, Wang F, Ehlers MD (2011) Activity-induced remodeling of olfactory bulb mi- crocircuits revealed by monosynaptic tracing. PLoS One 6:e29423. CrossRef Medline

Arevian AC, Kapoor V, Urban NN (2008) Activity-dependent gating of lateral inhibition in the mouse olfactory bulb. Nat Neurosci 11:80-87. CrossRef Medline

Balu R, Pressler RT, Strowbridge BW (2007) Multiple modes of synaptic excitation of olfactory bulb granule cells. J Neurosci 27:5621-5632. CrossRef Medline

Bathellier B, Lagier S, Faure P, Lledo PM (2006) Circuit properties generating gamma oscillations in a network model of the olfactory bulb. J Neurophysiol 95:2678-2691. Medline

Bathellier B, Buhl DL, Accolla R, Carleton A (2008) Dynamic ensemble odor coding in the mammalian olfactory bulb: sensory information at different timescales. Neuron 57:586-598. CrossRef Medline

Borisovska M, McGinley MJ, Bensen A, Westbrook GL (2011) Loss of olfactory cell adhesion molecule reduces the synchrony of mitral cell activity in olfactory glomeruli. J Physiol 589:1927-1941. CrossRef Medline

Boyd AM, Sturgill JF, Poo C, Isaacson JS (2012) Cortical feedback control of olfactory bulb circuits. Neuron 76:1161-1174. CrossRef Medline

Bozza T, McGann JP, Mombaerts P, Wachowiak M (2004) In vivo imaging of neuronal activity by targeted expression of a genetically encoded probe in the mouse. Neuron 42:9-21. CrossRef Medline

Buiakova OI, Baker H, Scott JW, Farbman A, Kream R, Grillo M, Franzen L, Richman M, Davis LM, Abbondanzo S, Stewart CL, Margolis FL (1996) Olfactory marker protein (OMP) gene deletion causes altered physiological activity of olfactory sensory neurons. Proc Natl Acad Sci U S A 93: 9858-9863. CrossRef Medline

Burton SD, Urban NN (2014) Greater excitability and firing irregularity of tufted cells underlies distinct afferent-evoked activity of olfactory bulb mitral and tufted cells. J Physiol 592:2097-2118. CrossRef Medline

Bywalez WG, Patirniche D, Rupprecht V, Stemmler M, Herz AV, Pálfi D, Rózsa B, Egger V (2015) Local postsynaptic voltage-gated sodium channel activation in dendritic spines of olfactory bulb granule cells. Neuron 85:590-601. CrossRef Medline

Cang J, Isaacson JS (2003) In vivo whole-cell recording of odor-evoked synaptic transmission in the rat olfactory bulb. J Neurosci 23:4108-4116. Medline

Carleton A, Petreanu LT, Lansford R, Alvarez-Buylla A, Lledo PM (2003) Becoming a new neuron in the adult olfactory bulb. Nat Neurosci 6:507518. CrossRef Medline

Cazakoff BN, Lau BY, Crump KL, Demmer HS, Shea SD (2014) Broadly tuned and respiration-independent inhibition in the olfactory bulb of awake mice. Nat Neurosci 17:569-576. CrossRef Medline

Chen WR, Xiong W, Shepherd GM (2000) Analysis of relations between NMDA receptors and GABA release at olfactory bulb reciprocal synapses. Neuron 25:625-633. CrossRef Medline

Chiu CQ, Lur G, Morse TM, Carnevale NT, Ellis-Davies GC, Higley MJ (2013) Compartmentalization of GABAergic inhibition by dendritic spines. Science 340:759-762. CrossRef Medline

Cleland TA (2010) Early transformations in odor representation. Trends Neurosci 33:130-139. CrossRef Medline

Clements JD, Bekkers JM (1997) Detection of spontaneous synaptic events with an optimally scaled template. Biophys J 73:220-229. CrossRef Medline

Cury KM, Uchida N (2010) Robust odor coding via inhalation-coupled transient activity in the mammalian olfactory bulb. Neuron 68:570-585. CrossRef Medline

De Saint Jan D, Hirnet D, Westbrook GL, Charpak S (2009) External tufted cells drive the output of olfactory bulb glomeruli. J Neurosci 29:20432052. CrossRef Medline

Deshpande A, Bergami M, Ghanem A, Conzelmann KK, Lepier A, Götz M, Berninger B (2013) Retrograde monosynaptic tracing reveals the temporal evolution of inputs onto new neurons in the adult dentate gyrus and olfactory bulb. Proc Natl Acad Sci U S A 110:E1152-E1161. CrossRef Medline

Egger V (2008) Synaptic sodium spikes trigger long-lasting depolarizations and slow calcium entry in rat olfactory bulb granule cells. Eur J Neurosci 27:2066-2075. CrossRef Medline

Egger V, Urban NN (2006) Dynamic connectivity in the mitral cell-granule cell microcircuit. Semin Cell Dev Biol 17:424-432. Medline

Egger V, Svoboda K, Mainen ZF (2005) Dendrodendritic synaptic signals in olfactory bulb granule cells: local spine boost and global low-threshold spike. J Neurosci 25:3521-3530. CrossRef Medline 
Eyre MD, Antal M, Nusser Z (2008) Distinct deep short-axon cell subtypes of the main olfactory bulb provide novel intrabulbar and extrabulbar GABAergic connections. J Neurosci 28:8217-8229. CrossRef Medline

Eyre MD, Kerti K, Nusser Z (2009) Molecular diversity of deep short-axon cells of the rat main olfactory bulb. Eur J Neurosci 29:1397-1407. CrossRef Medline

Feng G, Mellor RH, Bernstein M, Keller-Peck C, Nguyen QT, Wallace M, Nerbonne JM, Lichtman JW, Sanes JR (2000) Imaging neuronal subsets in transgenic mice expressing multiple spectral variants of GFP. Neuron 28:41-51. CrossRef Medline

Fletcher ML, Masurkar AV, Xing J, Imamura F, Xiong W, Nagayama S, Mutoh H, Greer CA, Knöpfel T, Chen WR (2009) Optical imaging of postsynaptic odor representation in the glomerular layer of the mouse olfactory bulb. J Neurophysiol 102:817-830. CrossRef Medline

Friedman D, Strowbridge BW (2003) Both electrical and chemical synapses mediate fast network oscillations in the olfactory bulb. J Neurophysiol 89:2601-2610. CrossRef Medline

Fukunaga I, Berning M, Kollo M, Schmaltz A, Schaefer AT (2012) Two distinct channels of olfactory bulb output. Neuron 75:320-329. CrossRef Medline

Fukunaga I, Herb JT, Kollo M, Boyden ES, Schaefer AT (2014) Independent control of gamma and theta activity by distinct interneuron networks in the olfactory bulb. Nat Neurosci 17:1208-1216. CrossRef Medline

Galán RF, Fourcaud-Trocmé N, Ermentrout GB, Urban NN (2006) Correlation-induced synchronization of oscillations in olfactory bulb neurons. J Neurosci 26:3646-3655. CrossRef Medline

Garcia I, Quast KB, Huang L, Herman AM, Selever J, Deussing JM, Justice NJ, Arenkiel BR (2014) Local CRH signaling promotes synaptogenesis and circuit integration of adult-born neurons. Dev Cell 30:645-659. CrossRef Medline

Gire DH, Schoppa NE (2009) Control of on/off glomerular signaling by a local GABAergic microcircuit in the olfactory bulb. J Neurosci 29:1345413464. CrossRef Medline

Gire DH, Franks KM, Zak JD, Tanaka KF, Whitesell JD, Mulligan AA, Hen R, Schoppa NE (2012) Mitral cells in the olfactory bulb are mainly excited through a multistep signaling path. J Neurosci 32:2964-2975. CrossRef Medline

Giridhar S, Urban NN (2012) Mechanisms and benefits of granule cell latency coding in the mouse olfactory bulb. Front Neural Circuits 6:40. CrossRef Medline

Grimes WN, Zhang J, Graydon CW, Kachar B, Diamond JS (2010) Retinal parallel processors: more than 100 independent microcircuits operate within a single interneuron. Neuron 65:873-885. CrossRef Medline

Grunditz A, Holbro N, Tian L, Zuo Y, Oertner TG (2008) Spine neck plasticity controls postsynaptic calcium signals through electrical compartmentalization. J Neurosci 28:13457-13466. CrossRef Medline

Halabisky B, Strowbridge BW (2003) Gamma-frequency excitatory input to granule cells facilitates dendrodendritic inhibition in the rat olfactory bulb. J Neurophysiol 90:644-654. CrossRef Medline

Halabisky B, Friedman D, Radojicic M, Strowbridge BW (2000) Calcium influx through NMDA receptors directly evokes GABA release in olfactory bulb granule cells. J Neurosci 20:5124-5134. Medline

Hall BJ, Delaney KR (2002) Contribution of a calcium-activated nonspecific conductance to NMDA receptor-mediated synaptic potentials in granule cells of the frog olfactory bulb. J Physiol 543:819-834. CrossRef Medline

Heinbockel T, Hamilton KA, Ennis M (2007a) Group I metabotropic glutamate receptors are differentially expressed by two populations of olfactory bulb granule cells. J Neurophysiol 97:3136-3141. CrossRef Medline

Heinbockel T, Laaris N, Ennis M (2007b) Metabotropic glutamate receptors in the main olfactory bulb drive granule cell-mediated inhibition. J Neurophysiol 97:858-870. CrossRef Medline

Higley MJ (2014) Localized GABAergic inhibition of dendritic Ca(2+) signalling. Nat Rev Neurosci 15:567-572. CrossRef Medline

Hines ML, Carnevale NT (1997) The NEURON simulation environment. Neural Comput 9:1179-1209. CrossRef Medline

Huang L, Garcia I, Jen HI, Arenkiel BR (2013) Reciprocal connectivity between mitral cells and external plexiform layer interneurons in the mouse olfactory bulb. Front Neural Circuits 7:32. CrossRef Medline

Igarashi KM, Ieki N, An M, Yamaguchi Y, Nagayama S, Kobayakawa K, Kobayakawa R, Tanifuji M, Sakano H, Chen WR, Mori K (2012) Parallel mitral and tufted cell pathways route distinct odor information to differ- ent targets in the olfactory cortex. J Neurosci 32:7970-7985. CrossRef Medline

Isaacson JS, Strowbridge BW (1998) Olfactory reciprocal synapses: dendritic signaling in the CNS. Neuron 20:749-761. CrossRef Medline

Isaacson JS, Vitten H (2003) GABA(B) receptors inhibit dendrodendritic transmission in the rat olfactory bulb. J Neurosci 23:2032-2039. Medline

Ivic L, Pyrski MM, Margolis JW, Richards LJ, Firestein S, Margolis FL (2000) Adenoviral vector-mediated rescue of the OMP-null phenotype in vivo. Nat Neurosci 3:1113-1120. CrossRef Medline

Kapoor V, Urban NN (2006) Glomerulus-specific, long-latency activity in the olfactory bulb granule cell network. J Neurosci 26:11709-11719. CrossRef Medline

Kass MD, Moberly AH, McGann JP (2013a) Spatiotemporal alterations in primary odorant representations in olfactory marker protein knockout mice. PLoS One 8:e61431. CrossRef Medline

Kass MD, Moberly AH, Rosenthal MC, Guang SA, McGann JP (2013b) Odor-specific, olfactory marker protein-mediated sparsening of primary olfactory input to the brain after odor exposure. J Neurosci 33:65946602. CrossRef Medline

Kato HK, Chu MW, Isaacson JS, Komiyama T (2012) Dynamic sensory representations in the olfactory bulb: modulation by wakefulness and experience. Neuron 76:962-975. CrossRef Medline

Kato HK, Gillet SN, Peters AJ, Isaacson JS, Komiyama T (2013) Parvalbuminexpressing interneurons linearly control olfactory bulb output. Neuron 80:12181231. CrossRef Medline

Kishi K, Mori K, Ojima H (1984) Distribution of local axon collaterals of mitral, displaced mitral, and tufted cells in the rabbit olfactory bulb. J Comp Neurol 225:511-526. CrossRef Medline

Kosaka T, Kosaka K (2007) Heterogeneity of nitric oxide synthasecontaining neurons in the mouse main olfactory bulb. Neurosci Res 57: 165-178. CrossRef Medline

Kosaka T, Kosaka K (2010) Heterogeneity of calbindin-containing neurons in the mouse main olfactory bulb: I. General description. Neurosci Res 67:275-292. CrossRef Medline

Labarrera C, London M, Angelo K (2013) Tonicinhibition sets the state of excitability in olfactory bulb granule cells. J Physiol 591:1841-1850. CrossRef Medline

Lagier S, Carleton A, Lledo PM (2004) Interplay between local GABAergic interneurons and relay neurons generates gamma oscillations in the rat olfactory bulb. J Neurosci 24:4382-4392. CrossRef Medline

Lee AC, He J, Ma M (2011) Olfactory marker protein is critical for functional maturation of olfactory sensory neurons and development of mother preference. J Neurosci 31:2974-2982. CrossRef Medline

Lepousez G, Lledo PM (2013) Odor discrimination requires proper olfactory fast oscillations in awake mice. Neuron 80:1010-1024. CrossRef Medline

Lepousez G, Csaba Z, Bernard V, Loudes C, Videau C, Lacombe J, Epelbaum J, Viollet C (2010) Somatostatin interneurons delineate the inner part of the external plexiform layer in the mouse main olfactory bulb. J Comp Neurol 518:1976-1994. CrossRef Medline

Lepousez G, Valley MT, Lledo PM (2013) The impact of adult neurogenesis on olfactory bulb circuits and computations. Annu Rev Physiol 75:339363. CrossRef Medline

LiG, Cleland TA (2013) A two-layer biophysical model of cholinergic neuromodulation in olfactory bulb. J Neurosci 33:3037-3058. CrossRef Medline

Liu WL, Shipley MT (1994) Intrabulbar associational system in the rat olfactory bulb comprises cholecystokinin-containing tufted cells that synapse onto the dendrites of GABAergic granule cells. J Comp Neurol 346: 541-558. CrossRef Medline

Luo M, Katz LC (2001) Response correlation maps of neurons in the mammalian olfactory bulb. Neuron 32:1165-1179. CrossRef Medline

Marella S, Ermentrout B (2010) Amplification of asynchronous inhibitionmediated synchronization by feedback in recurrent networks. PLoS Comput Biol 6:e1000679. CrossRef Medline

Margrie TW, Schaefer AT (2003) Theta oscillation coupled spike latencies yield computational vigour in a mammalian sensory system. J Physiol 546:363-374. CrossRef Medline

Markopoulos F, Rokni D, Gire DH, Murthy VN (2012) Functional properties of cortical feedback projections to the olfactory bulb. Neuron 76 : 1175-1188. CrossRef Medline

Markram H, Toledo-Rodriguez M, Wang Y, Gupta A, Silberberg G, Wu C (2004) Interneurons of the neocortical inhibitory system. Nat Rev Neurosci 5:793-807. CrossRef Medline 
Meister M, Bonhoeffer T (2001) Tuning and topography in an odor map on the rat olfactory bulb. J Neurosci 21:1351-1360. Medline

Migliore M, Hines ML, McTavish TS, Shepherd GM (2010) Functional roles of distributed synaptic clusters in the mitral-granule cell network of the olfactory bulb. Front Integr Neurosci 4:122. CrossRef Medline

Migliore M, Cavarretta F, Hines ML, Shepherd GM (2014) Distributed organization of a brain microcircuit analyzed by three-dimensional modeling: the olfactory bulb. Front Comput Neurosci 8:50. CrossRef Medline

Miyamichi K, Shlomai-Fuchs Y, Shu M, Weissbourd BC, Luo L, Mizrahi A (2013) Dissecting local circuits: parvalbumin interneurons underlie broad feedback control of olfactory bulb output. Neuron 80:1232-1245. CrossRef Medline

Mombaerts P, Wang F, Dulac C, Chao SK, Nemes A, Mendelsohn M, Edmondson J, Axel R (1996) Visualizing an olfactory sensory map. Cell 87:675-686. CrossRef Medline

Mori K, Takagi SF (1978) An intracellular study of dendrodendritic inhibitory synapses on mitral cells in the rabbit olfactory bulb. J Physiol 279: 569-588. CrossRef Medline

Mori K, Kishi K, Ojima H (1983) Distribution of dendrites of mitral, displaced mitral, tufted, and granule cells in the rabbit olfactory bulb. J Comp Neurol 219:339355. CrossRef Medline

Nagayama S, Homma R, Imamura F (2014) Neuronal organization of olfactory bulb circuits. Front Neural Circuits 8:98. CrossRef Medline

Najac M, De Saint Jan D, Reguero L, Grandes P, Charpak S (2011) Monosynaptic and polysynaptic feed-forward inputs to mitral cells from olfactory sensory neurons. J Neurosci 31:8722-8729. CrossRef Medline

Neville KR, Haberly LB (2003) Beta and gamma oscillations in the olfactory system of the urethane-anesthetized rat. J Neurophysiol 90:3921-3930. CrossRef Medline

Nunez-Parra A, Maurer RK, Krahe K, Smith RS, Araneda RC (2013) Disruption of centrifugal inhibition to olfactory bulb granule cells impairs olfactory discrimination. Proc Natl Acad Sci U S A 110:14777-14782. CrossRef Medline

Nusser Z, Kay LM, Laurent G, Homanics GE, Mody I (2001) Disruption of GABA(A) receptors on GABAergic interneurons leads to increased oscillatory power in the olfactory bulb network. J Neurophysiol 86:2823-2833. Medline

Orona E, Scott JW, Rainer EC (1983) Different granule cell populations innervate superficial and deep regions of the external plexiform layer in rat olfactory bulb. J Comp Neurol 217:227-237. CrossRef Medline

Orona E, Rainer EC, Scott JW (1984) Dendritic and axonal organization of mitral and tufted cells in the rat olfactory bulb. J Comp Neurol 226:346356. CrossRef Medline

Oswald AM, Urban NN (2012) There and back again: the corticobulbar loop. Neuron 76:1045-1047. CrossRef Medline

Otazu GH, Chae H, Davis MB, Albeanu DF (2015) Cortical feedback decorrelates olfactory bulb output in awake mice. Neuron 86:1461-1477. CrossRef Medline

Pallotto M, Nissant A, Fritschy JM, Rudolph U, Sassoè-Pognetto M, Panzanelli P, Lledo PM (2012) Early formation of GABAergic synapses governs the development of adult-born neurons in the olfactory bulb. J Neurosci 32:9103-9115. CrossRef Medline

Panzanelli P, Bardy C, Nissant A, Pallotto M, Sassoè-Pognetto M, Lledo PM, Fritschy JM (2009) Early synapse formation in developing interneurons of the adult olfactory bulb. J Neurosci 29:15039-15052. CrossRef Medline

Pinato G, Midtgaard J (2005) Dendritic sodium spikelets and low-threshold calcium spikes in turtle olfactory bulb granule cells. J Neurophysiol 93: 1285-1294. Medline

Pinto DJ, Brumberg JC, Simons DJ, Ermentrout GB (1996) A quantitative population model of whisker barrels: re-examining the Wilson-Cowan equations. J Comput Neurosci 3:247-264. CrossRef Medline

Pouille F, Scanziani M (2001) Enforcement of temporal fidelity in pyramidal cells by somatic feed-forward inhibition. Science 293:1159-1163. CrossRef Medline

Pressler RT, Strowbridge BW (2006) Blanes cells mediate persistent feedforward inhibition onto granule cells in the olfactory bulb. Neuron 49:889904. CrossRef Medline

Pressler RT, Inoue T, Strowbridge BW (2007) Muscarinic receptor activation modulates granule cell excitability and potentiates inhibition onto mitral cells in the rat olfactory bulb. J Neurosci 27:10969-10981. CrossRef Medline

Pressler RT, Rozman PA, Strowbridge BW (2013) Voltage-dependent in- trinsic bursting in olfactory bulb Golgi cells. Learn Mem 20:459-466. CrossRef Medline

Price JL, Powell TP (1970a) The synaptology of the granule cells of the olfactory bulb. J Cell Sci 7:125-155. Medline

Price JL, Powell TP (1970b) The mitral and short axon cells of the olfactory bulb. J Cell Sci 7:631-651. Medline

Rall W, Shepherd GM, Reese TS, Brightman MW (1966) Dendrodendritic synaptic pathway for inhibition in the olfactory bulb. Exp Neurol 14: 44-56. CrossRef Medline

Reisert J, Yau KW, Margolis FL (2007) Olfactory marker protein modulates the cAMP kinetics of the odour-induced response in cilia of mouse olfactory receptor neurons. J Physiol 585:731-740. CrossRef Medline

Ressler KJ, Sullivan SL, Buck LB (1994) Information coding in the olfactory system: evidence for a stereotyped and highly organized epitope map in the olfactory bulb. Cell 79:1245-1255. CrossRef Medline

Restrepo D, Doucette W, Whitesell JD, McTavish TS, Salcedo E (2009) From the top down: flexible reading of a fragmented odor map. Trends Neurosci 32:525-531. CrossRef Medline

Rubin BD, Katz LC (1999) Optical imaging of odorant representations in the mammalian olfactory bulb. Neuron 23:499-511. CrossRef Medline

Schoppa NE (2006a) AMPA/kainate receptors drive rapid output and precise synchrony in olfactory bulb granule cells. J Neurosci 26:1299613006. CrossRef Medline

Schoppa NE (2006b) Synchronization of olfactory bulb mitral cells by precisely timed inhibitory inputs. Neuron 49:271-283. CrossRef Medline

Schoppa NE, Urban NN (2003) Dendritic processing within olfactory bulb circuits. Trends Neurosci 26:501-506. Medline

Schoppa NE, Westbrook GL (1999) Regulation of synaptic timing in the olfactory bulb by an A-type potassium current. Nat Neurosci 2:11061113. CrossRef Medline

Schoppa NE, Kinzie JM, Sahara Y, Segerson TP, Westbrook GL (1998) Dendrodendritic inhibition in the olfactory bulb is driven by NMDA receptors. J Neurosci 18:6790-6802. Medline

Schreiber S, Fellous JM, Whitmer D, Tiesinga P, Sejnowski TJ (2003) A new correlation-based measure of spike timing reliability. Neurocomputing 52-54:925-931. CrossRef

Simões-de-Souza FM, Antunes G, Roque AC (2014) Electrical responses of three classes of granule cells of the olfactory bulb to synaptic inputs in different dendritic locations. Front Comput Neurosci 8:128. CrossRef Medline

Smear M, Shusterman R, O’Connor R, Bozza T, Rinberg D (2011) Perception of sniff phase in mouse olfaction. Nature 479:397-400. CrossRef Medline

Spors H, Grinvald A (2002) Spatio-temporal dynamics of odor representations in the mammalian olfactory bulb. Neuron 34:301-315. CrossRef Medline

Spors H, Wachowiak M, Cohen LB, Friedrich RW (2006) Temporal dynamics and latency patterns of receptor neuron input to the olfactory bulb. J Neurosci 26:1247-1259. CrossRef Medline

St John JA, Key B (2005) Olfactory marker protein modulates primary olfactory axon overshooting in the olfactory bulb. J Comp Neurol 488: 61-69. CrossRef Medline

Stroh O, Freichel M, Kretz O, Birnbaumer L, Hartmann J, Egger V (2012) NMDA receptor-dependent synaptic activation of TRPC channels in olfactory bulb granule cells. J Neurosci 32:5737-5746. CrossRef Medline

Tan J, Savigner A, Ma M, Luo M (2010) Odor information processing by the olfactory bulb analyzed in gene-targeted mice. Neuron 65:912-926. CrossRef Medline

Toida K, Kosaka K, Heizmann CW, Kosaka T (1996) Electron microscopic serial-sectioning/reconstruction study of parvalbumin-containing neurons in the external plexiform layer of the rat olfactory bulb. Neuroscience 72:449-466. CrossRef Medline

Urban NN, Arevian AC (2009) Computing with dendrodendritic synapses in the olfactory bulb. Ann N Y Acad Sci 1170:264-269. CrossRef

Vassar R, Chao SK, Sitcheran R, Nuñez JM, Vosshall LB, Axel R (1994) Topographic organization of sensory projections to the olfactory bulb. Cell 79:981-991. CrossRef Medline

Wachowiak M (2011) All in a sniff: olfaction as a model for active sensing. Neuron 71:962-973. CrossRef Medline

Wachowiak M, Cohen LB (2001) Representation of odorants by receptor neuron input to the mouse olfactory bulb. Neuron 32:723-735. CrossRef Medline 
Wachowiak M, Shipley MT (2006) Coding and synaptic processing of sensory information in the glomerular layer of the olfactory bulb. Semin Cell Dev Biol 17:411-423. CrossRef Medline

Wellis DP, Kauer JS (1994) GABAergic and glutamatergic synaptic input to identified granule cells in salamander olfactory bulb. J Physiol 475:419430. CrossRef Medline

Wellis DP, Scott JW (1990) Intracellular responses of identified rat olfactory bulb interneurons to electrical and odor stimulation. J Neurophysiol 64: 932-947. Medline

Woolf TB, Shepherd GM, Greer CA (1991a) Serial reconstructions of granule cell spines in the mammalian olfactory bulb. Synapse 7:181-192. CrossRef Medline

Woolf TB, Shepherd GM, Greer CA (1991b) Local information processing in dendritic trees: subsets of spines in granule cells of the mammalian olfactory bulb. J Neurosci 11:1837-1854. Medline

Youngentob SL, Margolis FL (1999) OMP gene deletion causes an elevation in behavioral threshold sensitivity. Neuroreport 10:15-19. CrossRef Medline

Youngentob SL, Kent PF, Margolis FL (2003) OMP gene deletion results in an alteration in odorant-induced mucosal activity patterns. J Neurophysiol 90:3864-3873. CrossRef Medline

Youngentob SL, Pyrski MM, Margolis FL (2004) Adenoviral vector-mediated rescue of the OMP-null behavioral phenotype: enhancement of odorant threshold sensitivity. Behav Neurosci 118:636-642. CrossRef Medline

Youngstrom IA, Strowbridge BW (2015) Respiratory modulation of spontaneous subthreshold synaptic activity in olfactory bulb granule cells recorded in awake, head-fixed mice. J Neurosci 35:8758-8767. CrossRef Medline

Yu Y, McTavish TS, Hines ML, Shepherd GM, Valenti C, Migliore M (2013) Sparse distributed representation of odors in a large-scale olfactory bulb circuit. PLoS Comput Biol 9:e1003014. CrossRef Medline

Yu Y, Migliore M, Hines ML, Shepherd GM (2014) Sparse coding and lateral inhibition arising from balanced and unbalanced dendrodendritic excitation and inhibition. J Neurosci 34:13701-13713. CrossRef Medline

Zelles T, Boyd JD, Hardy AB, Delaney KR (2006) Branch-specific $\mathrm{Ca}^{2+}$ influx from $\mathrm{Na}^{+}$-dependent dendritic spikes in olfactory granule cells. J Neurosci 26:30-40. CrossRef Medline 